\title{
1 Adaptor linked K63 di-Ubiquitin activates Nedd4/Rsp5 E3 ligase
}

2 Lu Zhu ${ }^{1,2}$, Qing Zhang ${ }^{1,2}$, Ciro Cordeiro ${ }^{1,2}$, Sudeep Banjade ${ }^{1,2}$, Richa Sardana ${ }^{1,2}$, Yuxin Mao ${ }^{1,2}$, Scott D. Emr ${ }^{1,2}$

3

1 Weill Institute for Cell and Molecular Biology, Cornell University, Ithaca, NY.

5

2 Department of Molecular Biology and Genetics, Cornell University, Ithaca, NY.

6 Correspondence to Lu Zhu: 1z232@cornell.edu; or Scott D.Emr: sde26@,cornell.edu

7 Key words: K63 di-ubiquitin, Need4/Rsp5, E3 ligase, adaptor, ubiquitination

8 Running title: The K63 di-Ubiquitination of Need4/Rsp5 adaptors 


\section{Abstract}

10 Nedd4/Rsp5 family E3 ligases mediate numerous cellular processes, many of which require the

11 E3 ligase to interact with PY-motif containing adaptor proteins. Several Arrestin-Related

12 Trafficking adaptors(ARTs) of Rsp5 were self-ubiquitinated for activation, but the regulation

13 mechanism remains elusive. Remarkably, we demonstrate that Art1, Art4, and Art5 undergo K63-

14 linked di-ubiquitination by Rsp5. This modification enhances the PM recruitment of Rsp5 by Art1

15 or Art5 upon substrate induction, required for cargo protein ubiquitination. In agreement with these

16 observations, we find that di-ubiquitin strengthens the interaction between the Pombe orthologs of

17 Rsp5 and Art1, Pub1 and Any1. Further, we discover that the HECT domain exosite protects the

18 K63-linked di-ubiquitin on the adaptors from cleavage by the deubiquitination enzyme Ubp2.

19 Strikingly, loss of this protection results in the loss of K63-linked di-ubiquitin from the adaptors

20 and diverts the adaptors for K48-linked poly-ubiquitination and proteasome-mediated degradation.

21 Together, our study uncovers a novel ubiquitination modification implemented by Rsp5 adaptor

22 proteins, underscoring the regulatory mechanism of how adaptor proteins control the recruitment

23 and activity of Rsp5 for the turnover of membrane proteins. 


\section{Introduction}

25 The Nedd4/Rsp5 family E3 ligases are responsible for membrane protein ubiquitination, required

26 for endocytosis and lysosome-dependent protein degradation. Tryptophan-tryptophan (WW)

27 domains of Nedd4 family E3 ligases bind to substrate proteins via interaction with PY motifs

28 containing a consensus sequence P/L-P-x-Y (Rotin \& Kumar, 2009; Schild et al, 1996). Other

29 substrates lack PY motifs and instead rely on interactions with adaptor proteins that recruit the

30 Nedd4 E3 ligase to them, exemplified by a family of arrestin-related trafficking adaptors (ARTs)

31 that bridge the association between substrates and Rsp5 for ubiquitination(Lin et al, 2008).

32 Additionally, Rsp5 adaptors include a diverse group of transmembrane (TM) proteins to mediate

33 degradation of membrane proteins localized at the PM, Golgi, endosome and vacuole membrane

34 (Alvaro et al, 2014; Becuwe et al, 2012; Hatakeyama et al, 2010; Hettema et al, 2004; Hovsepian

35 et al, 2018; Leon et al, 2008; Li et al, 2015; MacDonald et al, 2012; Nikko \& Pelham, 2009;

36 O'Donnell et al, 2013; Sardana et al, 2018; Zhu et al, 2020)

37

38 Many of the Nedd4/Rsp5 adaptor proteins undergo self-ubiquitination. The ART proteins Art1,

39 Art4 and Art8 require specific ubiquitination by Rsp5 to reach full activity (Becuwe et al., 2012;

40 Hovsepian et al, 2017; Lin et al., 2008). Ubiquitination of Nedd4 adaptor protein Commissureless

41 is required to downregulate the Robo receptor at the cell surface of axons, essential for midline

42 crossing (Ing et al, 2007; Myat et al, 2002). The N-lobe region of the Nedd4/Rsp5 family E3

43 ligase HECT domain contains an exosite which binds ubiquitin and has been shown to orient the

44 ubiquitin chain to promote conjugation of the next ubiquitin molecule of the growing polyubiquitin

45 chain(Kim et al, 2011; Maspero et al, 2011). It was proposed that ubiquitinated Rsp5 adaptors are

46 more active when locked onto Rsp5 but less active when unlocked by Ubp2 (MacDonald et al, 
47 2020). However, the mechanism of how Nedd4/Rsp5 adaptor ubiquitination helps enhance E3

48 ligase function remains unclear.

50 In this study, we decoded the activation mechanism of how adaptor protein ubiquitination

51 enhances E3 ligase function and how this ubiquitination itself is regulated by the deubiquitination

52 (DUB) enzyme Ubp2. Remarkably, we discovered that the Rsp5 adaptors Art1, Art4, and Art5 are

53 conjugated with K63-linked di-Ub at specific ubiquitination sites. Ubiquitination of Art5 and Art1

54 enhances Rsp5 recruitment to the plasma membrane thereby promoting substrate ubiquitination.

55 Our analysis of the binding affinity of di-Ub or isolated PY motifs to Rsp5 targeted domains

56 uncovered that K63-linked di-Ub conjugation to the adaptor protein Any1 sharply enhances its

57 binding to E3 ligase Pub1. Strikingly, we found that deletion of UBP2 rescues the deubiquitination

58 of adaptor proteins Art5 and Art1 in the rsp5-exosite mutant. Our data reveals the interplay

59 between Ubp2 and "Rsp5 exosite engagement" to modulate adaptor protein ubiquitination and

60 catalyze the switch from K63-linked di-Ub to K48-linked ubiquitin chains. Taken together, these

61 results serve as a portal for future studies of Nedd4/Rsp5 adaptor proteins in general.

62

63 Results

\section{Rsp5 adaptor protein Art5 undergoes K63-linked di-ubiquitination}

65 In yeast, $14 \alpha$-arrestin domain containing proteins have been identified: Art1-Art10(Lin et al., 66 2008; Nikko \& Pelham, 2009), Bul1-Bul3 (Yashiroda et al, 1996) and Spo23 (Aubry \& Klein,

67 2013). These proteins have clear arrestin sequence signatures and contain multiple PY motifs that

68 specifically interact with the WW domains in Rsp5 (Baile et al, 2019), and can recruit Rsp5 to

69 specific intracellular locations. This interaction not only results in ubiquitination of cargo proteins,

70 but also ubiquitination of ARTs themselves. In fact, several $\alpha$-arrestin domain containing proteins 
71 have been shown to be ubiquitinated by Rsp5, including Bul1, Bul2, Art1, Art4, Art5, Art6 and

72 Art8. Among these, Art5 contains an $\alpha$-arrestin domain and three C-terminal PY motifs (figure

73 1A). It has been shown that Art5 is the only ART protein required for the inositol-induced

74 endocytosis and degradation of the plasma membrane (PM) inositol transporter Itr1 (Nikko \&

75 Pelham, 2009).

77 We found that at steady state, endogenous Art5 migrates in two major bands by SDS-PAGE, 78 corresponding to the ubiquitinated and non-ubiquitinated species (Lane 2 in the Fig. 1B). Mass

79 spectrometry has previously indicated that ubiquitin is mainly conjugated on the K-364 residue of

80 the Art5 $\alpha$-arrestin domain (Swaney et al, 2013). We confirmed that Art5 ubiquitination was nearly

81 completely ablated by mutating K364(Fig. 1B, lane 3), and is completely abolished in the $\operatorname{art}^{\Delta \mathrm{PY}}$

82 mutant in which all three PY motifs were mutated (lane 4), demonstrating that Art5 ubiquitination

83 depends on its interaction with Rsp5 via PY motifs. There is a minor portion (albeit weak) of PY

84 motifs dependent Art5 higher molecular weight species (lane 2), probably due to other lysines.

85 Strikingly, the molecular weight difference $(\sim 20 \mathrm{KDa})$ between the non-ubiquitinated and

86 ubiquitinated forms of Art5 appears to be more than one single ubiquitin ( $9 \mathrm{KDa})$, suggesting

87 more than one ubiquitin molecule is conjugated to the Art5 protein. To test this hypothesis, we

88 fused the C-terminus of $\operatorname{art}^{\Delta \mathrm{PY}}$ with $1,2,3$ or 4 ubiquitin molecules to create $\operatorname{art5^{\Delta \mathrm {PY}}}-1 \mathrm{xUb}$, $89 \operatorname{art5}^{\triangle \mathrm{PY}}-2 \mathrm{xUb}$, art $5^{\triangle \mathrm{PY}}-3 \mathrm{xUb}$ and $\operatorname{art}^{\Delta \mathrm{PY}}-4 \mathrm{xUb}$, respectively. Remarkably, the ubiquitinated $90 \mathrm{Art} 5^{\mathrm{WT}}$ runs in line with $\operatorname{art} 5^{\triangle \mathrm{PY}}-2 \mathrm{xUb}$, indicating that Art5 is di-ubiquitinated mainly at the $\mathrm{K}$ -

91364 residue (Lane 4, 5 and 6 of Fig. 1B). 
93 We next asked what is the linkage in the di-ubiquitin that is conjugated to Art5. Rsp5 mainly

94 catalyzed K63-linked ubiquitin chain synthesis in vivo and in vitro (Lauwers et al, 2009; Saeki et

95 al, 2009). We therefore decided to examine whether the di-ubiquitin moiety on Art5 is K63-linked.

96 We analyzed the migration of $\mathrm{Art5} 5^{\mathrm{WT}}$, $\operatorname{art} 5^{\mathrm{K} 364 \mathrm{R}}$, and $\operatorname{art} 5^{\mathrm{APY}}$ proteins in yeast strains expressing

97 Ub-WT and Ub-K63R. Notably, as seen in Figure 1C, we found that the size of the di-ubiquitinated

98 Art5 band (lane 2 and 3) is reduced to the mono-ubiquitinated band (lane 9 and 10), in line with

$99 \operatorname{art}^{\Delta \mathrm{PY}}-1 \mathrm{xUb}$. As expected, this mono-Ub was conjugated to $\mathrm{K} 364$ residue. We noticed the loss of

100 Art5 protein in the Ub-K63R mutant in a K364 and PY motif dependent manner (lane 9, figure

101 1c), which will be discussed later. In addition, the mono-ubiquitinated band of Art5 in the yeast

$102 \mathrm{Ub}-\mathrm{K} 63 \mathrm{R}$ mutant is K364 residue dependent, confirming that the mono-ubiquitin is conjugated

103 mainly at the K364 residue. These data are consistent with the alignment with $\operatorname{art} 5^{\Delta \mathrm{PY}}-2 \mathrm{xUb}$ ? (Fig.

104 1C), indicating that endogenous Art5 is di-ubiquitinated. Together, our result demonstrate that

105 Art5 protein is di-Ubiquitinated at residue K364 in a K63 linkage by Rsp5.

107 Besides Art5, we next addressed if other ART proteins also undergo K63-linked di-ubiquitination.

108 To test this idea, we employed the same approach to analyze another ART family member, Art1.

109 Art1 was found to mediate downregulation of plasma membrane nutrient transporters such as Can1,

110 Mup1, Fur4, and Lyp1. Art1 contains an N-terminal arrestin fold with PY motifs near its C-

111 terminus (Fig. S1A), which bind to Rsp5's WW domains. The K486 residue is required for Art1

112 ubiquitination (Lin et al., 2008). As anticipated, the ubiquitinated form of Art1 shows the same

113 mobility shift in comparison with $\operatorname{art}^{\Delta \mathrm{PY}}-2 \mathrm{xUb}$ (Fig. S1B). To test if Art1 is ubiquitinated in a

$114 \mathrm{~K} 63$ linkage, we expressed the Art $1^{\mathrm{WT}}$, $\operatorname{art} 1^{\mathrm{K} 486 \mathrm{R}}$ and $\operatorname{art}^{\Delta \mathrm{PY}}$ in a yeast strain expressing only Ub- 
$115 \mathrm{~K} 63 \mathrm{R}$. The ubiquitinated band of Art1 migrates with $\operatorname{art}^{\Delta \mathrm{PY}}-2 \mathrm{xUb}$ in the Ub-WT strain, while

116 Art1 is mono-ubiquitinated at K486 in the yeast strain bearing Ub-K63R (Fig. S1C).

118 In addition to Art5 and Art1, another $\alpha$-arrestin domain containing protein, Art4, also interacts

119 with Rsp5 via PY motifs and can be ubiquitinated at a cluster of lysines (K235, K245, K264 and

120 K267) in the N-terminal arrestin domain (Becuwe et al., 2012), as shown in Figure S1E. To

121 examine the Art4 ubiquitination status, we expressed the Art4 ${ }^{\mathrm{WT}}$, art4 ${ }^{4 \mathrm{KR}}$ and $\operatorname{art}^{\Delta \mathrm{PY}}$ proteins in

122 the yeast strains expressing Ub-WT and Ub-K63R. Due to Art4 phosphorylation when cells were

123 grown in lactate medium, Art4 protein lysates were treated with phosphatase after being shifted to

124 glucose containing culture medium. The ubiquitinated form of Art4 ${ }^{\mathrm{WT}}$ migrates with the $\operatorname{art}^{\Delta \mathrm{PY}}$ -

$1252 \mathrm{xUb}$ (Fig. S1F). In contrast, Art4 ${ }^{\mathrm{WT}}$ was only mono-ubiquitinated in Ub-K63R condition. Taken

126 together, our results demonstrated that $\alpha$-arrestin domain containing adaptor proteins Art1, Art4

127 and Art5 are di-ubiquitinated and the di-ubiquitin is K63 linked (Fig. 1D, S1D and S1G).

128

\section{Ubiquitination of Art5 is required for cargo protein Itr1 ubiquitination}

130 As shown in the figure 1B, Art5 ubiquitination depends on the interaction with Rsp5 and is

131 abrogated in the Art5 K364R mutant. We therefore sought to investigate how Art5 ubiquitination

132 affects efficient inositol-dependent endocytosis and protein degradation of Itr1. To determine

133 whether Art5 ubiquitination is important for Art5 function, we expressed Art5 $5^{\mathrm{WT}}$ and $\operatorname{art} 5^{\mathrm{K} 364 \mathrm{R}}$ in

134 an $\operatorname{art} 5 \Delta$ mutant bearing a chromosomal Itr1-GFP. Itr1-GFP degradation occurs after treatment

135 with inositol in a dose-dependent manner. Thus, higher inositol concentrations applied for the same

136 amount of time results in more Itr1-GFP degradation in the WT cells (Fig. 2A, lane 5-8; Fig. 2C)

137 and protein sorting into the vacuole lumen (Fig. 2B, middle panels), and this endocytosis and 
138 degradation is Art5 dependent(Fig.2A, lane 1-4; Fig. 2C) (Nikko and Pelham, 2009). Cells

139 expressing $a r t 5^{\mathrm{K} 364 \mathrm{R}}$ caused a severe decrease in the rate of Itr1-GFP degradation (Fig. 2A, lane 9-

140 12; Fig. 2C) and protein endocytosis (Fig. 2B, right) at higher inositol concentrations compared

141 with Art5-WT. Thus, Art5 ubiquitination is essential to promote efficient Itr1 endocytosis and

142 protein degradation upon inositol-treatment.

143

144 We hypothesize that the Itr1 sorting defect in $\operatorname{art} 5^{\mathrm{K} 364 \mathrm{R}}$ is due to defective Itr1 ubiquitination. To

145 test it, we expressed Itr1-GFP in a doa4d mutant bearing a Myc-Ub expression vector to stabilize

146 ubiquitinated membrane proteins after multivesicular body sorting into the vacuole. After inositol

147 treatment, Itr1-GFP was immunoprecipitated from cell lysates prepared from yeast expressing

$148 \mathrm{Art}^{\mathrm{WT}}$ and $\operatorname{art} 5^{\mathrm{K} 364 \mathrm{R}}$. The ubiquitinated pool of Itr1-GFP can be detected in the Art5 ${ }^{\mathrm{WT}}$ condition,

149 whereas this ubiquitination was attenuated in $\operatorname{art} 5^{\mathrm{K} 364 \mathrm{R}}$ condition (Fig. 2D). We next asked if the

150 ubiquitination defect of $\operatorname{Itr} 1$ is due to the loss of protein-protein interaction between $\operatorname{art} 5^{\mathrm{K} 364 \mathrm{R}}$ and

151 Itr1. To test this, Itr1-GFP was immunoprecipitated from yeast strains expressing Art5 ${ }^{\mathrm{WT}}$ or

$152 \operatorname{art5}^{\mathrm{K} 364 \mathrm{R}}$ (Fig. 2E). $\operatorname{art5}^{\mathrm{K} 364 \mathrm{R}}$ can be co-immunoprecipitated by Itr1-GFP comparable to Art5 ${ }^{\mathrm{WT}}$,

153 indicating that the decrease of Itrt1 ubiquitination upon inositol stimulation is not due to the loss

154 of interaction between adaptor protein Art5 and cargo protein Itr1.

155

156 The importance of ubiquitination of the ART proteins in cargo protein sorting is further supported

157 by our previous findings that the $\operatorname{art} 1^{\mathrm{K} 486 \mathrm{R}}$ allele results in a canavanine hypersensitivity phenotype

158 (Lin et al., 2008). Here, we set out to test the endocytosis and protein degradation of Mup1-GFP

159 in $\mathrm{Art1}^{\mathrm{WT}}$ and $\operatorname{art}^{\mathrm{K} 486 \mathrm{R}}$ after treatment with increased methionine concentrations. Consistent with

160 previous results, the $\operatorname{art} 1^{\mathrm{K} 486 \mathrm{R}}$ allele leads to a sorting defect of Mup1-GFP (Fig. S2A, S2B and 
161 S2C). Similarly, we sought to test if the Mup1-GFP can bind to both Art ${ }^{\mathrm{WT}}$ and $\operatorname{art}^{\mathrm{K} 486 \mathrm{R}}$. To do

162 so, we examined the protein interaction between Mup1 and Art1 using co-IP analysis. Indeed, we

163 can observe the interaction between Mup1 and overexpressed Art1 (Fig. S2D). In agreement with

164 previous finding that the acidic patch in the Mup1 N-terminal tail is required for binding with Art1

165 (Guiney et al, 2016), we showed that the Q49R Mup1 mutant did not interact with Art1 (Fig. S2E).

166 Further, both Art $1^{\mathrm{WT}}$ and $\operatorname{art} 1^{\mathrm{K} 486 \mathrm{R}}$ can bind to Mup1, as evidenced by the Co-IP of $\operatorname{art}^{\mathrm{K} 486 \mathrm{R}}$ with

167 Mup1 when Art1 ubiquitination is impaired (Fig. S2F). Thus, our results demonstrate that the

168 sorting defect of Mup1-GFP in the presence of $\operatorname{art} 1^{\mathrm{K} 486 \mathrm{R}}$ is not due to the loss of protein interaction

169 between the adaptor protein Art1 and cargo protein Mup1.

170

171 Since TORC1 kinase regulates the Art1-dependent ubiquitin-mediated cargo protein endocytosis

172 by modulating Art1 phosphorylation via Npr1 kinase (MacGurn et al, 2011), we decided to test if

173 the non-ubiquitinated pool of Art1 loses the Nprl dependence for phosphorylation thereby

174 affecting cargo protein sorting. First, we expressed Art1 ${ }^{\mathrm{WT}}$ or $\operatorname{art} 1^{\mathrm{K} 486 \mathrm{R}}$ in $\mathrm{WT}$ and $n p r 1 \Delta$ mutant

175 strains. We observed that both the di-ubiquitinated Art1 or the non-ubiquitinated Art1 pools

176 migrated slightly faster in the npr $1 \Delta$ mutant, consistent with dephosphorylation (Fig. S2G). Next,

177 we treated the cells with either rapamycin or cycloheximide to monitor the change in

178 phosphorylation status for ubiquitinated or non-ubiquitinated Art1. As shown in the figure S2H,

179 the activated Npr1 kinase triggered by rapamycin treatment leads to phosphorylation of both

$180 \mathrm{Art}^{\mathrm{WT}}$ and $\operatorname{art} 1^{\mathrm{K} 486 \mathrm{R}}$; whereas the dephosphorylation of these two proteins is observed following

181 cycloheximide treatment. The Npr1 kinase-dependent phosphorylation is therefore the intrinsic

182 feature of Art1, regardless of the ubiquitination status of Art1. 
184 Since ARTs ubiquitination enhances function, we next sought to test if C-terminal fusion with

185 ubiquitin molecules could rescue the cargo sorting defect of $\operatorname{artl}^{\mathrm{K} 486 \mathrm{R}}$ or $\operatorname{artl}^{\Delta \mathrm{PY}}$. Since toxic

186 arginine analog canavanine is transported by PM transporter Can 1 in yeast and Can1 endocytosis

187 prevents subsequent cell death (Grenson et al, 1966), canavanine hypersensitivity occurs when

188 Can1 cannot be endocytosed (such as in an artls mutant), which provides a readout of Art1

189 function. Thus, we examined the canavanine sensitivity of the art $1 \Delta$ mutant expressing Art ${ }^{\text {WT }}$,

$190 \operatorname{art}^{\mathrm{K} 486 \mathrm{R}}$ or $\operatorname{artl}^{\triangle \mathrm{PY}}$ fused with $\mathrm{C}$-terminal $1 \mathrm{x}, 2 \mathrm{x}$ or $3 \mathrm{xUb}$. The $\mathrm{C}$-terminal fusions with ubiquitin

191 molecules did not enhance the functionality of $\operatorname{Art}^{\mathrm{WT}} \operatorname{art}^{\mathrm{K} 486 \mathrm{R}}$ or $\operatorname{art}^{\Delta \mathrm{PY}}$ (Fig. S2I, S2J). Besides

192 Art1, we tested if Itr1-GFP sorting can be restored by art $5^{\mathrm{K} 364 \mathrm{R}}$ with C-terminal 1xUb or $2 \mathrm{xUb}$ and

193 found the $1 \mathrm{x}$ or $2 \mathrm{xUb}$ fusions do not enhance the Itr1 sorting (Fig. 2F). Together, our data indicate

194 that di-ubiquitin needs to be conjugated at specific residues for proper functionality.

195

196

\section{PM recruitment of Rsp5 is enhanced by Art5 and Art1 protein ubiquitination}

197 The $\operatorname{art} 5^{\mathrm{K} 364 \mathrm{R}}$ mutant partially blocks the ubiquitination and cargo sorting of Itr1 after inositol 198 treatment (Figure 2A and 2D), but still interacts with Itr1. We therefore hypothesize that the defective ubiquitination of $a r t 5^{\mathrm{K} 364 \mathrm{R}}$ may impair Rsp5 recruitment to the PM. To test this idea, we examined the localization of Art5-GFP in yeast cells before and after inositol treatment. As seen in figure 3A, the Art5 ${ }^{\mathrm{WT}}$-GFP localized at cytosol, nucleus and occasional cytosolic puncta (Sec7negative, Figure 3A). Strikingly, the Art5 ${ }^{\mathrm{WT}}$-GFP is re-localized to PM puncta and patch structures 
207 and $\operatorname{art5}^{\Delta \mathrm{PY}}$ mainly remain in the cytosol even after inositol treatment (Figure 3B-D). We conclude

208 that ubiquitination of Art5 is important for protein re-localization to the PM upon inositol treatment.

209 We next asked if Rsp5 can be re-localized to the PM in an Art5-dependent manner after adding

210 inositol to the growth media. As expected, Rsp5 was observed to be recruited to PM patches after

211 inositol treatment in WT cells. However, Rsp5 PM recruitment after inositol treatment was

212 substantially reduced in cells expressing either $\operatorname{art}^{\mathrm{K} 364 \mathrm{R}}$ or $\operatorname{art5}^{\Delta \mathrm{PY}}$ (Figure $3 \mathrm{E}$ and $3 \mathrm{~F}$ ).

213

214 In addition to Art5, we also examined the PM localization of Art1 upon methionine treatment. Our

215 previous results showed that Art1 is localized to Golgi, PM and cytosol, whereas the $\operatorname{artl}^{\mathrm{K} 486 \mathrm{R}}$

216 mutant is mainly localized to the cytosol(Baile et al., 2019; Lin et al., 2008). Artl is recruited to

217 the PM during cargo downregulation upon cycloheximide treatment or shift from synthetic

218 medium to rich medium (Lin et al., 2008). As seen in the figure S3A, Art1 is efficiently recruited

219 to the PM in YPD or in methionine media. In contrast to Art1 ${ }^{\mathrm{WT}}$, the recruitment of $\operatorname{artl}^{\mathrm{K} 486 \mathrm{R}}$ to

220 the $\mathrm{PM}$ is largely attenuated and no $\mathrm{PM}$ recruitment is seen with $\operatorname{artl}^{\triangle \mathrm{PY}}$ (Figure $\mathrm{S} 3 \mathrm{~B}, \mathrm{~S} 3 \mathrm{C}$ ). We

221 next tested whether Art1 facilitates PM recruitment of Rsp5. As expected, methionine treatment

222 induces Rsp5 PM recruitment in cells expressing WT Art1, but this recruitment is much reduced

223 in cells expressing $\operatorname{art} 1^{\mathrm{K} 486 \mathrm{R}}$ (Figure S3E, S3F). Taken together, our results support the model that

224 specific ubiquitination of adaptor proteins is required for proper recruitment of Rsp5 to target

225 membranes and subsequent ubiquitin-mediated endocytosis of cargo proteins.

227 Substrate dependent PM recruitment of adaptor protein Art5 and Art1

228 Next, we sought to examine if cargo proteins are required for adaptor protein recruitment to their

229 functional locations. To do so, we examined the Art5-GFP PM recruitment in ITRI-WT and itr1 $\Delta$ 
mutants upon inositol treatment for 1 hour. Strikingly, we found that the PM recruitment of Art5-

GFP is abolished in the itrls mutant (Figure 3G, 3H). Similarly, we observed that the PM

232

recruitment of Art1 is attenuated in the mup $1 \Delta$ mutant with methionine induction for 1 hour (figure

$\mathrm{S} 3 \mathrm{G}$ and $\mathrm{S} 3 \mathrm{H})$. We further tested whether Artl can be recruited to the PM in cells expressing

is unable to be endocytosed with methionine treatment (Guiney et al., 2016) and the mup1-Q49R

mutation abolishes the protein-protein interaction between Mup1 and Art1 (Figure S2E). We

expected that PM recruitment of Art1 will be impaired in this mutant due to the loss of the interaction between Art1 and Mup1-Q49R. Indeed, PM recruitment of Art1 is abrogated in the mup1-Q49R condition (Figure $\mathrm{S} 3 \mathrm{G}$ and $\mathrm{S} 3 \mathrm{H}$ ), suggesting that the Mup1-Art1 interaction is required for methionine-induced Art1 PM re-localization. Collectively, our data demonstrate that the substrate proteins (Itr1 and Mup1) are required for adaptor protein (Art5 and Art1) recruitment to target membranes (Fig. 3I).

\section{K63-linked di-ubiquitination enhances the interaction between adaptor proteins and Rsp5}

We found that the Rsp5 adaptor proteins (Art5, Art1, and Art4) undergo K63-linked diubiquitination and this modification is required for efficient recruitment of Rsp5 to target membranes and cargo protein degradation. We hypothesized that adaptor di-ubiquitination

promotes the recruitment of the E3 ligase. To test this hypothesis, we set out to examine the binding 
253 Spence et al, 1995). Then, we performed a binding assay between glutathione- $S$-transferase (GST)

254 fusion proteins to Rsp5 HECT domain or GST only and the K63-linked ubiquitin chains. The 255 mono-Ub and K63-linked di-ubiquitin chains bind to GST-HECT domain (lane 7), but not to GST

256 (Figure 4A). The binding between mono-Ub and HECT domain depends on the exosite/ubiquitin

257 interface (Y516 and F618) (French et al, 2009; Kim et al., 2011); we found that the binding

258 between K63-linked di-Ub and HECT domain is disrupted by the exosite mutants Y516A, F618A,

259 or the Y516A/F618A double mutant (lane 8, 9 and 10 of Figure 4A), suggesting that the K63-

260 linked di-Ub also interacts with the HECT domain via the exosite.

261

262 Each Need4 family E3 ligase contains a HECT domain. It was shown that HECT domains of

263 various Nedd4 family HECT E3 ligases (Maspero et al., 2011), as well as the Rsp5 HECT domain

264 (Kim et al., 2011), are able to interact with mono-Ubiquitin. Since we have shown that adaptor

265 proteins are di-ubiquitinated in a K63-linkage, we next decided to examine the interaction between

266 HECT domains and mono-Ub and K63-linked di-Ub. The dissociation constant (Kd) for the

267 interaction between HECT and mono-ubiquitin was quantified by isothermal titration calorimetry

268 (ITC) assay to be approximately $201 \mu \mathrm{M}$ (Figure 4B). We also employed the Rsp5 HECT exosite

269 mutant (F618A) as a negative control. In agreement with the in-vitro GST-binding assay result in

270 figure 4A, no binding was detected between mono-ubiquitin and HECT domain mutant (F618A,

271 shown in the figure 4B). Ubiquitin is often recognized through a hydrophobic surface containing

272 Ile44, which is bound by most Ubiquitin Binding Domains (UBDs) (Dikic et al, 2009; Shih et al,

273 2000; Sloper-Mould et al, 2001). We therefore included the ubiquitin binding mutant (I44A)

274 serving as a negative control here. As expected, the I44A mutation of ubiquitin abolishes the

275 binding between mono-ubiquitin and the HECT domain (Figure 4B). Our results suggest that the 
276 HECT domain exosite and the I44-containing ubiquitin hydrophobic surface are required to bridge

277 the protein-protein interaction between the HECT domain and ubiquitin. In contrast to the mono-

278 ubiquitin results, $\mathrm{K} 63$-linked di-Ub enhances the binding affinity $\mathrm{Kd}=33 \mu \mathrm{M}$, nearly 6 -fold relative

279 to the mono-Ub (Figure 4C). In line with the in-vitro GST binding result, we examined the binding

280 between K63-linked di-Ub and the HECT domain mutant (F618A) by ITC and found that the

281 protein-protein interaction is abolished. Head-to-tail M1-linked di-Ub was proposed to mimic the

282 K63 ubiquitin linkage (Komander et al, 2009; Zhu et al, 2017). As expected, our ITC analysis

283 showed that M1 linked di-Ub binds to HECT with $\mathrm{Kd}=36 \mu \mathrm{M}$, comparable with the K63-linked di-

$284 \mathrm{Ub}$ (Fig. 4D). In line with this result, our in-vitro binding assay showed that the binding between

285 GST-2xUb and HECT domain is stronger than GST-Ub (Fig. 4E). In comparison, K48-linked di-

$286 \mathrm{Ub}$ shows a much lower affinity than $\mathrm{K} 63-\mathrm{di}-\mathrm{Ub}, \mathrm{Kd}=145 \mu \mathrm{M}$ (Fig. 4F). Together, our results

287 demonstrate that HECT domain specifically binds to linear form K63 di-Ub and the exosite site is

288 required for ubiquitin binding.

289

290 We next wondered if both the proximal and distal end ubiquitin of the K63-linked di-Ub, or just

291 the distal end Ub, contribute the binding to the HECT domain. Since Ile44 of ubiquitin is essential

292 for binding of ubiquitin to HECT domain (Fig.4B), we fused a distal end Ub (I44A) mutant to a

293 proximal $\mathrm{Ub}(\mathrm{WT})$ and generated the distal end I44A mutant of K63 di-Ub $\left(\mathrm{Ub}^{\mathrm{I} 44 \mathrm{~A}}-\mathrm{Ub}^{\mathrm{WT}}\right)$. The

294 Ile44 residue of the proximal end ubiquitin is essential for ubiquitin binding by Ubc13/Mms2 and

295 critical for K63-linked di-Ub catalysis, the Ile44 mutant of the proximal end ubiquitin of the K63

296 di-Ub cannot be made (Tsui et al, 2005). We found that the K63-linked $\mathrm{Ub}^{\mathrm{I} 44 \mathrm{~A}}-\mathrm{Ub}^{\mathrm{WT}}$ binds to

297 HECT with an $\mathrm{Kd}=120 \mu \mathrm{M}$, lower binding affinity than the $\mathrm{K} 63 \mathrm{di}-\mathrm{Ub}$ (Fig. 4G). Thus, our result 
suggests that both distal and proximal ubiquitins contribute to the HECT domain binding, probably

299 cooperatively.

300

301

302

We next sought to determine if K63-linked di-Ub enhances the binding between adaptor and HECT type E3 ligase. In spite of the fact that KR mutants of Art5 and Art1 lead to attenuated Rsp5 PM recruitment and cargo proteins (Itr1 and Mup1), we still observed the interaction between Art1-K486R or Art5-K364R with Rsp5 using Co-IP (Fig. 4H, 4I), probably due to the interaction between the PY motifs and WW domains. Indeed, as shown in the figure (Fig. 4J, 4K), Art1 and Art5 PY motif containing peptides interact with purified WW domains from $\mathrm{Rsp} 5(\mathrm{Kd}=3.6 \mu \mathrm{M}$ for Art1 PY motifs and $\mathrm{Kd}=3.1 \mu \mathrm{M}$ for Art5 PY motifs), but not with PY motif mutants. Since the sole interaction between PY motifs and WW domains does not suffice the full activation of Rsp5 function (Fig. 2A and S2A), the interaction between di-Ub and HECT may enhance the binding affinity between Need4/Rsp5 E3 ligases and their adaptors. We next sought to test the binding between full length adaptors and Rsp5. We found that we could not express Art1 or Art5 at high levels in E. coli, then tried to express the Art1 orthologue from S. pombe, Any1, in E.coli. We found the $S$. pombe Rsp5 ortholog Pub1 interacts with Any1 with a binding affinity $\mathrm{Kd} \sim 2.1 \mu \mathrm{M}$ (Fig. 4L), in a similar range as the binding affinity between PY motifs and WW domains shown earlier (Fig. 4J, 4K). Remarkably, Anyl conjugated with K63 di-Ub enhances the binding with Pub1 over 10-fold in comparison with non-conjugated Any1 (Figure 4M), suggesting that di-Ub conjugation onto Any1 probably leads to a structural conformation change of Any1 and therefore enhances the binding with Pub1. This result is in agreement with our previous result that diubiquitination of Art5 and Art1 are required for efficient Rsp5 recruitment to the plasma membrane and for cargo protein sorting. Taken together, the di-ubiquitination of adaptor proteins enhances 
321 the binding affinity with the E3 ligase, leading to E3 ligase recruitment and cargo protein

322 ubiquitination and sorting.

\section{Deubiquitination of K63 di-Ub of adaptor protein Art5 by Ubp2}

325 Given that the exosite of Rsp5 is essential for binding with the di-Ub on adaptor proteins, we next

326 examined the ubiquitination status for the adaptor proteins Art1 and Art5. The di-ubiquitinated

327 form of Art5 is diminished in the rsp5-F618A mutant (Fig. 5A, lane 2). Similarly, the di-

328 ubiquitinated pool of Art1 is substantially attenuated in either the Y516A or F618A exosite mutant

329 (Fig. S4A). Maspero and coworkers reported that exosite mutants do not alter the binding affinity

330 between E3 and E2 enzymes, the transthiolation process from E2 to E3, or the self-ubiquitination

331 activity of Nedd4 (Maspero et al., 2011). We therefore speculated that a deubiquitination enzyme

332 (DUB) is involved in the trimming process of the K63-linked di-Ub. To test this hypothesis, we

333 performed a multicopy gene suppression screen with all budding yeast DUBs . As shown in Figure

$334 \mathrm{~S} 4 \mathrm{~B}$, overexpressing Ubp2 by a $T D H 3$ promoter leads to a reduction of the di-ubiquitinated portion

335 of Art1. Further, we overexpressed the catalytic dead mutant C745V of Ubp2 and found that the

336 deubiquitination of Art1 is restored (Fig. S4C). This result infers that Ubp2 may function as a DUB

337 to trim the di-ubiquitinated form of Rsp5 adaptor proteins.

339 To investigate the role of Ubp2 in the modification of Rsp5 adaptor proteins, we examined the 340 adaptor protein Art5 in a double mutant of $r s p 5$-exosite (F618A) and $u b p 2 \Delta$. Strikingly, the di341 ubiquitinated Art5 and Art1 are nearly fully restored in the rsp5-F618A/ubp2 $\Delta$ strain (Fig. 5A,lane 342 4) and (Fig. S4D, lane 4), indicating that Ubp2 trims the di-ubiquitin on adaptors Art5 and Art1

343 when they are disengaged from the Rsp5 exosite. To test if Ubp2 is playing a catalytic or structural 
344 role in this process, we complemented the $r s p 5-\mathrm{F} 618 \mathrm{~A} / u b p 2 \Delta$ with either a wild-type or a catalytic

345 mutant $u b p 2-C 745 \mathrm{~V}$. We found that the Ubp2-WT (Fig. S4E lane 2) fully reverses the rescue of

346 Art1 trimming seen in the lane 1, whereas the $u b p 2-\mathrm{C} 745 \mathrm{~V}$ does not (Fig. S4E lane 3). Together,

347 these results suggest that the exosite can protect the di-ubiquitin moiety on adaptors from the

348 cleavage by Ubp2.

350 We next wondered if the loss of Art5 (Fig. 5A, lane 2) is mediated by proteasome function. To 351 answer this question, we treated the $r s p 5$-F618A mutant with proteasome inhibitor MG132. We

352 found that the full length Art5 protein is restored 2.8 fold with temporary inhibition of proteasome

353 function (Fig. 5B), suggesting that Art5 probably undergoes K48-linked polyubiquitination

354 because K48-linked ubiquitin chains are is preferred by the proteasome. As seen in figure 5B,

355 either the PY motif or the K364R mutant rescues the loss of Art5, indicating that Rsp5 is the E3

356 ligase responsible for Art5 degradation and the same site K364 is used for this ubiquitination

357 process. To directly determine the involvement of K63 versus K48 linkage in the Art5 degradation,

358 we examined the effect of overexpressing myc-ubiquitin with wild-type, K63R and K48R

359 mutations on Art5 ubiquitination. We found that expressing myc-ubiquitin K63R does not affect

360 Art5 hyperubiquitination in the rsp5-exosite mutant background, whereas the K48R ubiquitin

361 mutant substantially reduced Art5 ubiquitination (Fig. 5C). This result suggests that the Art5

362 ubiquitination in the rsp5-exosite mutant is mediated by a K48-linked polyubiquitin chain.

364 We then sought to uncover the mechanism by which the Art5 degradation is triggered. We

365 observed that Art5 protein is also degraded in the $U b-\mathrm{K} 63 \mathrm{R}$ mutant (Fig. 1C). We wondered if $366 u b p 2 \Delta$ can rescue Art5 degradation in the $U b$-K63R mutant. To test this, we deleted Ubp2 in the 
367

368

369

370

371

372

373

374

375

376

377

378

379

380

381

382

383

384

385

386

387

388 389

$U b$-K63R mutant and found that $u b p 2 \Delta$ does not reverse the loss of Art5 protein (Fig. 5D). Our results suggest that the loss of K63-di-Ub on Art5, instead of Ubp2, in either the $U b$-K63R mutant or $r s p 5$-exosite mutant, leads to Art5 degradation. Remarkably, in these two conditions, the Art5 degradation can be rescued in art5-K364R and art5- $\triangle \mathrm{PY}$ mutant (Fig. 5B and 5D). These data suggest that Rsp5 can mediate both K63 and K48-linked ubiquitination and the K364 residue of Art5 can be conjugated with both K63-linked di-Ub and K48-linked polyubiquitin chain. Collectively, our results support a working model that the K63-linked di-Ub on Art5 is fully engaged into the Rsp5 exosite so that Ubp2 cannot cleave it efficiently, whereas the K63-linked di-Ub is disengaged in an rsp5-exosite mutant therefore exposed to Ubp2 for cleavage. Upon the cleavage of K63-linked di-Ub, a K48-linked polyubiquitin chain is conjugated at the same residue Art5-K364 thereby leading to the proteasome-dependent degradation of Art5 (Fig. 5E-5H).

Since PM recruitment of Rsp5 is enhanced by Art5 or Art1 protein ubiquitination (Fig. 3E, S3E) and Ubp2 can deubiquitinate these adaptor proteins (Fig. 5A and S4D), we therefore asked if the adaptor ubiquitination process is reversible and $\mathrm{Ubp} 2$ is involved in this process or not. To monitor the pre-existing adaptor proteins, we decided to employ the tet-Off system to fix the pool of adaptor proteins by treating the cells with doxycycline. As seen in the figure S4F and S4G, pre-existing Art5 or Art1 undergoes ubiquitination upon inositol or methionine treatment for 1 hour in both WT and $u b p 2 \Delta$ conditions, whereas the adaptor proteins shifted back to less ubiquitinated status after removing the stimulation in the WT condition, but not in the $u b p 2 \Delta$ mutant. Together, our data demonstrate a model for adaptor protein recycling mediated by Ubp2 (Fig. S4H). First, stimulation enhances adaptor ubiquitination. Second, the ubiquitinated pool of adaptor proteins can be de-ubiquitinated by Ubp2 when stimulation is terminated. 


\section{Discussion}

392 In this study, we identified the first K63-linked di-Ub modification that modulates the function of

393 Rsp5 and adaptor proteins. Our data demonstrates that two biological functions are implicated with

394 this K63-linked di-Ub modification. First, K63-linked di-Ub activates Rsp5 function. K63-linked

$395 \mathrm{di}-\mathrm{Ub}$ enables the full engagement of adaptors onto the Rsp5 exosite and sharply enhances the

396 binding affinity with Rsp5, which facilitates Rsp5 recruitment and accelerates substrate protein

397 ubiquitination. Second, K63-linked di-Ub prevents the adaptors from being conjugated with K48-

398 linked polyubiquitin. K63-linked di-Ub on adaptors engaged with the Rsp5 exosite are not

399 accessible to Ubp2. Once released from Rsp5 exosite, the exposed K63-linked di-Ub is subjected

400 to cleavage by Ubp2 and K48-linked polyubiquitin subsequently can be conjugated onto the

401 adaptor protein, which signals proteasome-dependent protein degradation. Further, we monitored

402 the ubiquitination status of adaptor proteins Art1 and Art5. Using tet-Off system, we have shown

403 that adaptor proteins undergo ubiquitination upon stimulation and Ubp2 is required for

404 deubiquitination of adaptor proteins once the stimulation is removed. As hypothesized by our

405 earlier review (MacGurn et al, 2012), our current data supports the model that ubiquitinated

406 adaptor proteins were deubiquitinated by Ubp2 once released from Rsp5 exosite so that the adaptor

407 proteins can be recycled for the next round of ubiquitination event.

408

409 K63-linked di-Ub is engaged into Rsp5 E3 ligase for activation

410 While we showed that Rsp5 adaptors Art1, Art4 and Art5 undergo K63-linked di-Ub modification,

411 we also demonstrate that this conjugation sharply enhances the binding with the E3 ligase and

412 activates the E3 ligase function for substrate ubiquitination (Fig. 2D). We reason that the 
413 interaction between the di-Ub chain and the HECT domain locks the E3 ligase and adaptor into an

414 active/functional conformation. For adaptor-independent ubiquitination, the Nedd4/Rsp5 ligase

415 exosite is also required for efficient ubiquitin conjugation, demonstrating that the "Ub-exosite

416 binding" is required to localize and orient the distal end ubiquitin chain to promote conjugation

417 (Kim et al., 2011; Maspero et al., 2011). In terms of the Rsp5 adaptor- mediated function, we

418 propose that the binding between "di-Ub and exosite" not only enhances the binding affinity

419 between the E3 ligase and adaptor (Fig. 4L-4M), but also leads to more productive Rsp5

420 recruitment to properly orient and present the substrate for ubiquitination at target membranes (Fig.

$4213 B)$.

422

423 While we presented the evidence of E3 ligase activation by ubiquitinated adaptors, we also showed

424 that K63 di-Ub generates a 6-fold tighter binding to the HECT domain than mono-Ub. We reason

425 that the K63 di-Ub provides alternative options to bind a single site, but also fits with a model in

426 which there are multiple ubiquitin binding sites. It was found that three N-lobe mutations (Y516A,

427 F618A, and V621A/V622A) completely abolished ubiquitin binding and three extra mutations

428 (N513A, Y521A, and R651A) caused a reduction in binding (French et al., 2009). Kim and

429 coworkers found that the L8-I44-V70 hydrophobic patch of mono-Ub sits on Rsp5 in three legs,

430 like a tripod (Kim et al., 2011). Likewise, two separated UIMs in Rap80 bind to extended K63-

431 linked ubiquitin chain favorably (Sato et al, 2009; Sims \& Cohen, 2009). Indeed, we have shown

432 the results that K63-linked di-Ub with a mutation (I44A) at the distal end ubiquitin leads to lower

433 binding with Rsp5 (Figure 4G). We propose that multiple ubiquitin binding sites are probably

434 present at the Rsp5 exosite to accommodate the two hydrophobic patches of the distal and proximal

435 ubiquitins, which needs be addressed in the future by structural analysis. 
437 The linkage specificity and length control for the K63-linked di-Ub

438 We have been intrigued by the question of how the K63 linkage of di-Ub was achieved and

439 preferred, instead of K48. It is known that yeast Rsp5 and human Nedd4 mainly assemble K63-

440 linked ubiquitin chains (Kim \& Huibregtse, 2009; Maspero et al., 2011). The K48-linked di-Ub

441 binds the HECT domain, but not as tight as K63-linked di-Ub (Fig. 4F). Interestingly, both the

442 M1-linked and K63-linked di-Ubiquitins adopt an equivalent open conformation (Komander et al.,

443 2009) and exhibit similar binding affinity to the HECT domain (Fig. 4D), indicating that the HECT

444 domain exosite has a strong preference for the linear and extended form of di-Ub. In contrast, the

445 K48-linked polyubiquitin chain adopts a significantly distinct and compact structure (Eddins et al,

446 2007), which may not be favorable for the HECT domain exosite.

447

448 Why is the K63-linked di-Ub chain limited to a dimer? On the one hand, this probably correlates

449 with the physiological reversible function of adaptors. The K63-linked 3x or longer ubiquitin

450 chains likely generate stronger binding with the HECT domain than di-Ub (Fig. 4E). We reason

451 that the di-Ub binds well with the HECT domain, but still can be disengaged from the HECT

452 domain under physiological conditions so that Rsp5 can be disassociated and recycled. On the

453 other hand, the K63-linked di-Ub is probably just enough to be masked by the HECT domain

454 exosite cavity whereas longer chains will be trimmed by Ubp2. Future structural studies could

455 address the accessible region for the di-Ub isopeptide bond cleavage by Ubp2 when di-Ub is

456 engaged into the HECT domain. Further, a K63-linked polyubiquitin chain also can serve as a

457 targeting signal for proteasomal degradation (Ohtake et al, 2018; Saeki et al., 2009). We noticed

458 that hyperubiquitinated forms $(>2 \mathrm{xUb})$ of ART proteins are not stables since the linear form of 
$4593 \mathrm{xUb}$ leads to adaptor protein degradation (Lanes \#7 of the figures $1 \mathrm{C}, \mathrm{S} 2 \mathrm{C}$ and S2F). Indeed,

460 K63-linked polyubiquitin on Rsp5 adaptor proteins contributes to proteasomal degradation of the

461 adaptors (Ho et al, 2017).

462

463

464 Ubp2 mediates the recycling of Rsp5 E3 ligases from adaptors after ubiquitination

465 McDonald and coworkers proposed that several Rsp5 adaptors compete for Rsp5 and a Ubp2

466 deficiency increased both the adaptor activity and the ability to compete for Rsp5 (MacDonald et

467 al., 2020). Indeed, the PPxY motif containing Rsp5 adaptors share the E3 ligase Rsp5 and an

468 adaptor should disassociate from Rsp5 to allow other adaptors to engage with Rsp5 to ubiquitinate

469 different substrate proteins. In agreement with this working model, Nedd4-mediated

470 downregulation of the sodium channel $\mathrm{ENaC}$ is impaired when $\mathrm{Nedd} 4$ is sequestered by

471 overexpression of another Nedd4 E3 adaptor, Ndfip2 (Konstas et al, 2002).

472

473 Besides cleavage of K63 di-Ub in the rsp5-exosite mutant, Ubp2 allows the recycling of Rsp5

474 from its adaptor proteins. Since K63 di-Ub greatly enhances the binding affinity between adaptors

475 and E3 ligase (shown in figure 4), Ubp2 likely helps the Nedd4/Rsp5 E3 ligase to catalyze distinct

476 ubiquitination events by cleaving the di-Ub off the adaptors and recycling Rsp5. The multitasking

477 of Rsp5 via various adaptors leads us to hypothesize that activated Rsp5 can be released from

478 engaged adaptor proteins. We showed that the adaptor proteins Art1 and Art5 undergo di-

479 Ubiquitination upon environmental stimulation and Ubp2 is required to reverse this ubiquitination.

480 Once the ubiquitination is done, the engaged $\mathrm{K} 63$ di-Ub is exposed for cleavage by Ubp2. 
481 Thereafter, Ubp2 acts on ubiquitinated adaptor proteins to release the adaptor proteins and Rsp5.

482 The mechanism by which Ubp2 executes this reaction needs to be addressed in the future.

483

484 In summary, we propose that Rsp5 ubiquitinates adaptors to trigger their engagement with the

485 Rsp5 exosite, which enables the tight binding between adaptors and Rsp5 thereby activating Rsp5

486 function. Ubp2 acts as an antagonist for K63 di-Ub to modulate the interaction between K63-di-

$487 \mathrm{Ub}$ and the Rsp5 exosite in a reversible manner to maintain cellular homeostasis of Rsp5. Future

488 work needs to address the atomic structure of the ART family of adaptor proteins in complex with

489 Rsp5 in order to understand how di-Ub is attached to the adaptor and how the di-ubiquitinated

490 adaptors engage with the HECT E3 ligases, stabilizing an activated conformation of the E3 ligase. 
491

492

493

494

495

496

497

498

499

500

501

502

503

504

505

506

507

508

509

510

511

512 Protein Purification

\section{Material and Methods}

\section{Yeast strains, cloning, mutagenesis and cell growth conditions}

The ART1, ART4, ART5, ITR1, MUP1 and YUH1 genes were cloned from Saccharomyces cerevisiae yeast strain SEY6210. Pub1 (residue 287-767) and Any1 (residue 17-361) were PCR amplified from Schizosaccharomyces pombe yeast strain PR109 and subcloned into pET28a with an N-terminal 6xHis-SUMO tag. When necessary, the gene deletions and taggings were made using gene replacement technique with longtine-based PCR cassettes (Longtine et al., 1998). All yeast strains and plasmids are described in Tables S1 and S2. For fluorescent microscopy experiments, cells were grown overnight to mid-log phase (OD600 0.5) in synthetic media at $30^{\circ} \mathrm{C}$.

For inositol or methionine stimulation experiments, cells were grown in synthetic media to $\log$ phase (OD600 0.8) then treated with exogenous inositol and methionine at different concentrations. Ub-WT, Ub-K63R, Ub-K48R, Ub-D77, Mms2 and Ubc13 were PCR amplified from yeast strain SEY6210 genomic DNA and cloned into pET21a, pET28a-6xHIS and pGEX6p1 respectively. 1x, 2x, and 3x and 4x Ub head-to-tail fusions of Art1, Art4, Art5 expression and pGEX6p-1 vectors were made by Gibson assembly. E1 enzyme expression vector pET21a-Uba1 (human) and K48 ubiquitin linkage specific E2 enzyme E2-25K expression vector pGEX-6p-1E2-25K are from our lab stock. YUH1 was subcloned into pGEX6p-1 expression vector with an N-terminal GST tag. PY motifs containing regions for Art1 (661-710) and Art5 (520-586) were PCR amplified and cloned into pGEX-6p-1 vectors. Rsp5 HECT domain (444-809) and WW1HECT domain (224-809) were fused with N-terminal SUMO tag and cloned into pET28a vector. 
513 All pET21a, pET28a, pGEX6p-1 constructs were transformed into Escherichia coli strain Rosetta

514 (DE3) cells. Single colonies were then cultured in Luria-Bertani (LB) medium containing either

$515100 \mu \mathrm{g} / \mathrm{ml} \mathrm{Ampicillin} \mathrm{or} 50 \mu \mathrm{g} / \mathrm{ml}$ kanamycin to a density between 0.6 and $0.8 \mathrm{OD} 600$ at $37^{\circ} \mathrm{C}$.

516 Cultures were induced with $0.2 \mathrm{mM}$ isopropyl-B-D-thiogalactopyranoside (IPTG) at $18^{\circ} \mathrm{C}$ for 16

517 hours. E.coli cells were collected by centrifugation at 3,500 rpm for $15 \mathrm{~min}$ at $4^{\circ} \mathrm{C}$. For non-tagged

518 ubiquitin purification, cells were disrupted by sonication in the lysis buffer (50mM NH4Ac

519 (pH4.5rt), 2mM DTT, 1mM EDTA, 1mM PMSF). For 6xHIS-SUMO tagged proteins, cells were

520 sonicated in the lysis buffer (20 mM Tris ( $\mathrm{pH} 7.5), 150 \mathrm{mM} \mathrm{NaCl}, 2 \mathrm{mM}$ DTT, $1 \mathrm{mM}$ EDTA, $1 \mathrm{mM}$

521 PMSF). For GST fusion proteins, cells were disrupted in the lysis buffer $(200 \mathrm{mM} \mathrm{NaCl}, 25 \mathrm{mM}$

522 Tris.HCl pH8rt, 2mM EDTA, 2mM DTT, 1mM PMSF).

523

524 The lysate for Ub (WT, K63R, K48R, I44A, D77 or D77/I44A) was adjusted to pH4.5 then spun 525 down at $46,000 \mathrm{xg}$ for $45 \mathrm{~min}$ at $4^{\circ} \mathrm{C}$. The supernatant was heated at $70^{\circ} \mathrm{C}$ for 5 min then spun down

526 again with the same condition. The supernatant was loaded onto SP Sepharose Fast Flow resin

527 pre-equilibrated with the same lysis buffer ( $\mathrm{pH} 4.5)$. The Ub was eluted with 50mM ammonium

528 acetate (pH4.5 room temperature) buffer containing 2mM DTT using a linear gradient of 0-

$529500 \mathrm{mM} \mathrm{NaCl}$. The eluted Ub mutants were fractionated by Superdex 200-exclusion column then

530 dialyzed against size-exclusion buffer (20 mM Tris ( $\mathrm{pH} 7.5), 150 \mathrm{mM} \mathrm{NaCl}, 2 \mathrm{mM}$ DTT). Each

531 mutant was concentrated to $15 \mathrm{mg} / \mathrm{ml}$ and stored at $-80^{\circ} \mathrm{C}$.

532

533 For 6xHIS-SUMO-tagged (HECT, Pub1(287-767), Any1(17-361) and WW1-HECT) and GST-

534 tagged proteins (Ubc13, E2-25K, Yuh1, PY motifs of Art1 or Art5 and M1 linked Ub-Ub), the

535 sonicated lysates were centrifuged $46,000 \mathrm{xg}$ for $45 \mathrm{~min}$ at $4^{\circ} \mathrm{C}$. The supernatant was bound with 
536 TALON cobalt resin or Glutathione Sepharose 4 Fast Flow and the resins were digested by SUMO-

537 specific Ulp1 or GST-specific PreScission proteases to release the proteins of interest. The eluted

538 proteins were fractionated by Superdex 200 using size-exclusion buffer (20 mM Tris (pH 7.5), 150

$539 \mathrm{mM} \mathrm{NaCl}, 2 \mathrm{mM}$ DTT). Ubc13, E2-25K and Yuh1 were concentrated to $750 \mu \mathrm{M}$ with $20 \%$ glycerol

540 and the other proteins were concentrated to $1 \mathrm{mM}$ and stored at $-80^{\circ} \mathrm{C}$.

541

542 For 6xHis-tagged Uba1 and Mms2 purification, the E.coli cells were sonicated in lysis buffer 20

$543 \mathrm{mM}$ Tris ( $\mathrm{pH} 7.5), 150 \mathrm{mM} \mathrm{NaCl}, 2 \mathrm{mM}$ DTT, $c$ Omplete ${ }^{\mathrm{TM}}$ protease inhibitor). The cell lysate (per

5441 liter) was cleared by centrifugation at $46,000 \mathrm{xg}, 45 \mathrm{~min}, 4^{\circ} \mathrm{C}$. The supernatant was incubated with

545 cobalt-chelate TALON resin for 30min before column wash with lysis buffer supplemented with

$54625 \mathrm{mM}$ imidazole and the protein of interest was eluted with $300 \mathrm{mM}$ imidazole and dialyzed

547 against $50 \mathrm{mM}$ Tris- $\mathrm{HCl}(\mathrm{pH} 7.6)$ containing $2 \mathrm{mM}$ DTT and $0.1 \mathrm{mM}$ EDTA. The protein is

548 concentrated to $100 \mu \mathrm{M}$ with $20 \%$ of glycerol and stored at $-80^{\circ} \mathrm{C}$.

549

550 For GST-tagged protein (GST-1xUb, GST-2xUb and GST-3xUb) purification, the sonicated cell

551 lysate was spun down at $46,000 \mathrm{xg}, 45 \mathrm{~min}, 4^{\circ} \mathrm{C}$. The supernatant per 1 liter of cells was incubate

552 with $2 \mathrm{ml}$ of Glutathione Sepharose 4 Fast Flow resin and washed with 5 column volumes of wash

553 buffer (20mM Tris pH8rt, 200mM NaCl, 1mM DTT). The GST-tagged proteins were eluted by 2

554 column volumes of elution buffer (100mM Tris pH8.5, 20mM Glutathione) then dialyzed against

555 size-exclusion buffer (20 mM Tris ( $\mathrm{pH} 7.5), 150 \mathrm{mM} \mathrm{NaCl}, 2 \mathrm{mM}$ DTT). Each protein was

556 concentrated to $30 \mathrm{mg} / \mathrm{ml}$ and stored at $-80 \mathrm{oC}$.

557 
558 For synthesis of K63 or K48 di-Ub proteins, 5xPBDM buffer was prepared: $250 \mathrm{mM}$ Tris- $\mathrm{HCl}$

$559(50 \%, \mathrm{pH} 8.0$, or $\mathrm{pH} 7.6), 25 \mathrm{mM} \mathrm{MgCl}_{2}, 50 \mathrm{mM}$ creatine phosphate (Sigma P7396), $3 \mathrm{U} / \mathrm{mL}$ of

560 inorganic pyrophosphatase (Sigma I1891), and 3 U/mL of creatine phosphokinase (Sigma C3755).

561 K63 linked di-Ub is synthesized by incubating purified human E1 $(0.1 \mu \mathrm{M})$, yeast E2 (Ubc13 and

562 Mms2, 8$\mu \mathrm{M}$ of each), two ubiquitin mutants (K63R and D77, 5mg/ml of each), ATP (2.5mM),

$5631 \mathrm{mM}$ DTT and 1xPBDM buffer (pH7.6). For K48 linked di-Ub synthesis, purified human E1

$564(0.1 \mu \mathrm{M})$, E2-25K $(20 \mu \mathrm{M})$, two ubiquitin mutants (K48R and D77, $7.5 \mathrm{mg} / \mathrm{ml}$ of each), ATP

$565(2.5 \mathrm{mM}), 1 \mathrm{mM}$ DTT and 1xPBDM buffer (pH8.0) were mixed. The reaction mixtures of either

$566 \mathrm{~K} 63$ or $\mathrm{K} 48$ di-Ub were incubated at $37^{\circ} \mathrm{C}$ for overnight then the reaction was chilled on ice for

$56710 \mathrm{~min}$ to stop the reaction. 0.2 volume of $2 \mathrm{M}$ ammonium acetate was added to the reaction to

568 decrease the $\mathrm{pH}$ to less than 4.0. The mixture were loaded to SP Sepharose Fast Flow. The K63

569 di-Ub or K48 di-Ub mixtures were loaded onto Superdex 75 size-exclusion column using gel

570 filtration buffer (20mM Tris- $\mathrm{HCl}(\mathrm{pH} 7.5), 2 \mathrm{mM}$ DTT, $150 \mathrm{mM} \mathrm{NaCl})$ and the fractions of diUb

571 were pooled and concentrated.

572

\section{Synthesis and Purification of Any1-diUb}

574 To remove the D77 of the proximal Ub and unlock the carboxyl-terminal Gly-Gly of K63diUb for

575 further conjugation, purified $\mathrm{K} 63$ linked di-Ub $(30 \mathrm{mg} / \mathrm{ml})$ is exchanged into hydrolysis buffer $(50$

$576 \mathrm{mM}$ Tris-HCl pH 7.6, $1 \mathrm{mM}$ EDTA, and 1mM DTT) and treated with purified Yuh1 (final

577 concentration of $16 \mu \mathrm{g} / \mathrm{ml}$ ) for 60 minutes at $37^{\circ} \mathrm{C}$. After cooling down the reaction at room

578 temperature, 4mM DTT to the mixture is supplememted with DTT to $5 \mathrm{mM}$ (final concentration).

579 The reaction mixture was then applied to a $5 \mathrm{ml} \mathrm{Q}$ column equilibrated with $\mathrm{Q}$ buffer $(50 \mathrm{mM}$

580 Tris-HCl pH 7.6, 1 mM EDTA, 5 mM DTT). After 2 bed volumes of wash, the unbound K63 di- 
$581 \mathrm{Ub}$ (D77 removed) is collected and concentrated. Di-ubiquitination of Any1 was carried out by

582 incubating purified Any1 proteins with human E1(0.1 $\mu \mathrm{M})$, human E2(UbcH5C, $0.3 \mu \mathrm{M})$ and

583 Pub1 $(0.3 \mu \mathrm{M}), \mathrm{K} 63$ diUb (D77 removed, $10 \mu \mathrm{M})$, ATP (2.5mM), $1 \mathrm{mM}$ DTT and 1xPBDM

584 buffer ( $\mathrm{pH} 7.6)$ for $30 \mathrm{~min}$ at room temperature. The reaction mixture was chilled on ice before

585 loading onto Superdex 200 size-exclusion column using gel filtration buffer (150 mM NaCl, 20

586 mM HEPES pH 7.5), and fractions of Anyl-diUb were pooled and concentrated.

587

588 GST pull down assay

589 For pull-down experiments, $2 \mu \mathrm{M}$ of GST fusion proteins were immobilized onto $100 \mu \mathrm{L}$ of

590 glutathione bead slurry in the $1 \mathrm{ml}$ of pull down buffer $(50 \mathrm{mM} \mathrm{Na}-\mathrm{HEPES} \mathrm{pH} 7.5,150 \mathrm{mM} \mathrm{NaCl}$,

591 1mM EDTA, 1mM EGTA, 10\% Glycerol, 1\% Triton X-100). 500ng of Rsp5 HECT protein was

592 added to the mixture and incubated at $4^{\circ} \mathrm{C}$ for 2 hours. After 4 washes with pull down buffer,

593 specifically bound proteins were eluted by SDS-sample buffer and resolved on SDS-PAGE (11\%)

594 and detection was obtained by Coomassie-staining.

595

596 Isothermal Titration Calorimetry assay

597 Isothermal Titration Calorimetry (ITC) experiments were carried out on an Affinity-ITC 598 calorimeter (TA instruments) at $25^{\circ} \mathrm{C}$. Titration buffer contained $20 \mathrm{mM}$ Tris- $\mathrm{HCl}(\mathrm{pH} 7.5), 150$ $599 \mathrm{mM} \mathrm{NaCl}, 1 \mathrm{mM}$ DTT. For a typical experiment, each titration point was performed by injecting 600 a $2 \mu \mathrm{L}$ aliquot of protein sample $(50-1000 \mu \mathrm{M})$ into the cell containing $300 \mu \mathrm{L}$ of another reactant $601(5-300 \mu \mathrm{M})$ at a time interval of $200 \mathrm{~s}$ to ensure that the titration peak returned to the baseline.

602 The titration data was analyzed with NanoAnalyze v3.12.0 (TA instruments) using an independent 603 binding model. 


\section{Fluorescence microscopy assay}

606 For fluorescence microscopy, cells expressing GFP, pHluorin or mCherry proteins were visualized 607 using a DeltaVision Elite system (GE), equipped with a Photometrics CoolSnap HQ2/sCMOS

608 Camera, a 100×objective, and a DeltaVision Elite Standard Filter Set ('FITC' for GFP/pHluorin 609 fusion protein and 'mCherry' for mCherry fusion proteins). Image acquisition and deconvolution 610 were performed using Softworx.

611

612 Whole cell lysate extraction and western blotting

613 Whole cell extracts were prepared by incubating 6 ODs of cells in 10\% Trichloroacetic acid on ice

614 for 1 hour. Extracts were fully resuspended with ice-cold acetone twice by sonication, then

615 vacuum-dried. Dry pellets were mechanically lysed (3x 5min) with $100 \mu \mathrm{L}$ glass beads and 100

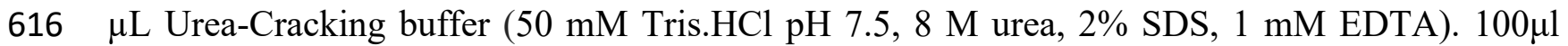

617 protein $2 \mathrm{x}$ sample buffer (150 mM Tris. $\mathrm{HCl} \mathrm{pH}$ 6.8, $7 \mathrm{M}$ urea, 10\% SDS, 24\% glycerol,

618 bromophenol blue) supplemented with 10\% 2-mercaptoethanol was added and samples were

619 vortexed for $5 \mathrm{~min}$. The protein samples were resolved on SDS-PAGE gels and then transferred to

620 nitrocellulose blotting membranes (GE Healthcare Life Sciences).

621

622 The flowing antibodies and dilutions were used in this study: Rabbit polyclonal anti-G6PDH 623 (1:30,000; SAB2100871; Sigma), Rabbit polyclonal anti-GFP (1:10,000; TP401; Torrypines), 624 Mouse monoclonal anti-GFP (1:1,000; B-2, sc-9996; Santa Cruz), Mouse monoclonal anti-Myc 625 (1:5,000, sc-40, Santa Cruz), IRDye® 800CW Goat anti-Mouse (1:10,000; 926-32210; LI-COR), 626 IRDye ${ }^{\circledR}$ 800CW Goat anti-Rabbit (1:10,000; 926-32211; LI-COR), IRDye® ${ }^{\circledR}$ 680LT Goat anti- 
627 Rabbit (1:10,000; 926-68021; LI-COR) and IRDye ${ }^{\circledR}$ 680LT Goat anti-Mouse(1:10,000; 925628 68070; LI-COR).

629

\section{Immunoprecipitation (IP) assay}

$631100 \mathrm{ODs}$ of cells were collected and washed with water at $4^{\circ} \mathrm{C}$. To examine the interaction between

632 Art1 and Mup1-GFP, between Art5 and Itr1-GFP, or between ARTs protein and Rsp5. Yeast cells

633 were washed with ice-cold water 3 times. The cells were lysed in $500 \mu 1$ of IP buffer $(20 \mathrm{mM}$

634 Tris.HCl, pH 7.5, 0.5 mM EDTA, pH 8.0, 0.5 mM EGTA, $0.5 \mathrm{mM} \mathrm{NaF,} 150 \mathrm{mM} \mathrm{NaCl,} 10 \%$

635 glycerol, $1 \mathrm{mM}$ PMSF, $10 \mathrm{mM}$ N-ethylmaleimide (NEM), and cOmplete Protease Inhibitor). Cell

636 extracts were prepared by glass-bead beating with $0.5-\mathrm{mm}$ zirconia beads for five cycles of 30

637 seconds vortexing with 1 minute breaks on ice. Membrane proteins were solubilized by adding

$638500 \mu 1$ of $1 \%$ Triton X-100 in IP buffer. The lysates were incubated at $4^{\circ} \mathrm{C}$ for 30 min with rotation

639 then spun at $500 \mathrm{xg}$ for $5 \mathrm{~min}$ at $4^{\circ} \mathrm{C}$. The supernatant was clarified by centrifugation at $16000 \mathrm{xg}$

640 for $10 \mathrm{~min}$. To detect the interaction between ARTs and Mup1 or Itr1-GFP proteins, the cleared

641 lysate was incubated with $50 \mu 1$ of GFP-nanotrap resin for 2 hours at $4^{\circ} \mathrm{C}$. To examine the

642 interaction between Rsp5 and ARTs, the cleared lysate was bound with $50 \mu 1$ of FLAG-M2 resin

643 (Sigma, A2220) at $4^{\circ} \mathrm{C}$ for 2 hour. After incubation, the resin was washed 5 times with $0.1 \%$ Triton

$644 \mathrm{X}-100$ in IP buffer and the bound protein was eluted by $50 \mu 1$ of $2 x$ sample buffer.

645

646 To examine the ubiquitination of Itr1, Cells were grown to early log phase in synthetic media.

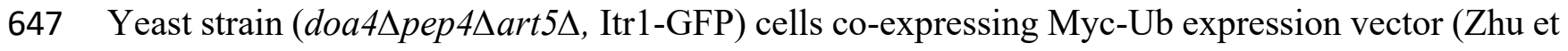

648 al., 2017) and Art5 ${ }^{\mathrm{WT}}$ or $\operatorname{art} 5^{K 364 R}$ were grown to mid-log phase in synthetic medium at $30^{\circ} \mathrm{C}$. Cells

649 were pretreated with $0.1 \mu \mathrm{M} \mathrm{CuCl} 2$ for 4 hours to induce the $\mathrm{Myc}-\mathrm{Ub}$ expression prior to inositol 
$650(20 \mu \mathrm{g} / \mathrm{ml})$ treatment. 100ODs of Cells were incubated with 10\% TCA buffer and the extracts were

651 washed with cold acetone. Dry pellets were mechanically lysed (3x 5min) with $100 \mu \mathrm{L}$ glass beads

652 and $100 \mu \mathrm{L}$ Urea-Cracking buffer (50 mM Tris. $\mathrm{HCl} \mathrm{pH}$ 7.5, $8 \mathrm{M}$ urea, 2\% SDS, $1 \mathrm{mM}$ EDTA,

653 200mM NEM). The cell lysates were mixed with $1 \mathrm{ml}$ of IP buffer (50 mM HEPES-KOH, $\mathrm{pH} 6.8$,

$654150 \mathrm{mM}$ KOAc, $2 \mathrm{mM} \mathrm{MgOAc}, 1 \mathrm{mM} \mathrm{CaCl} 2,20 \mathrm{mM}$ NEM and 15\% glycerol) with cOmplete $\mathrm{CM}^{\mathrm{TM}}$

655 protease inhibitor (Sigma-Aldrich, St. Louis, MO). The Cell lysates were clarified by spinning at

$65616,000 \mathrm{xg}$ for $10 \mathrm{~min}$ at $4^{\circ} \mathrm{C}$. The resulting lysate was then incubated with $50 \mu \mathrm{L}$ GFP-nanotrap

657 resin for 4 hours at $4^{\circ} \mathrm{C}$. The resin was washed 5 times with $0.1 \%$ Triton X-100 in IP buffer. Bound

658 protein was eluted by $50 \mu 1$ of $2 x$ sample buffer. Whole cell lysate and the IP reaction was resolved

659 on 10\% SDS-PAGE gels and the blots were probed with both GFP and Myc antibodies.

660

661 Quantification of westernblot band intensity

662 Westernblot in figures were quantified using Image-J software. The significance for protein 663 densities were determined two-tail $t$-test, $\alpha=0.05$ (Bonferroni correction), $\mathrm{n}=3$. n.s. indicates not

664 significant; $*, P<0.05 ; * *, P<0.01 ; * * *, P<0.001$.

665

666 Quantification of microscopy images

667 Images of GFP-Rsp5, Art5-GFP and Art1-mNG were taken by fluorescence microscopy. The

668 fluorescence signal of the target proteins at PM were selected and measured by Image-J. The

669 corrected total fluorescence of each selection $=$ Selected density - (Selected area X Mean

670 fluorescence of background readings). The ratio of GFP-Rsp5, Art5-GFP and Art1-mNG

671 recruitment to $\mathrm{PM}$ or vacuole $=($ The corrected fluorescence density of the target proteins localized 
672 at PM) / (The corrected fluorescence density). The ratios of GFP-Rsp5, Art5-GFP and Art1-mNG

673 recruitment were measured from $n=20$ cells.

674

\section{Acknowledgements}

676 We are grateful to Dr. Jason A. MacGurn, Dr. Matthew G. Baile, and Dr. Sho Suzuki for critical

677 reading of the manuscript. We also thank other members of the Emr lab for helpful discussions.

678 This work was supported by a Cornell University Research Grant (CU563704) to Scott D. Emr.

679 


\section{Main figure titles}

681 Figure 1. Art5 undergoes K63-linked di-ubiquitination.

682 Figure 2. Ubiquitinated Art5 promotes cargo protein Itr1 ubiquitination.

683 Figure 3. The Art5 di-ubiquitination is required for Rsp5 membrane recruitment.

684 Figure 4. K63-linked di-ubiquitination enhances the interaction between adaptor proteins and Rsp5.

685 Figure 5. Deubiquitination of K63 di-Ub of adaptor protein Art5 by Ubp2 


\section{Figure legends}

687 Figure 1. Art5 undergoes K63-linked di-ubiquitination. (A) Schematic representation of the

688 domain architecture of Art5. (B) A di-ubiquitin is conjugated at K364 residue of Art5. Western 689 blot analysis of Art5, $\operatorname{art5}^{K 364 R}, \operatorname{art5}^{\triangle P Y}, \operatorname{art5}^{\triangle P Y}-1 \mathrm{xUb}, \operatorname{art5}^{\Delta P Y_{-}}-2 \mathrm{xUb}, \operatorname{art5}^{\triangle P Y}-3 \mathrm{xUb}$ and $\operatorname{art5}^{\triangle P Y_{-}}$

$6904 \mathrm{xUb}$ in the wild-type strain. (C) Art5 is di-ubiquitinated in a K63 linkage at the residue K364.

691 Western blot analysis of Art5, art5 $5^{K 364 R}$, art5 $5^{\triangle P Y}$ in both the $U b-W T$ and $U b-K 63 R$ mutant strains.

692 (D) Model depicting the K63-linked di-ubiquitination of Art5 at the K364. The whole cell lysate 693 protein samples were resolved on 7\% SDS-PAGE gels and the blot was probed with FLAG and 694 GAPDH antibodies.

695

696 Figure 2. Ubiquitinated Art5 promotes cargo protein Itr1 ubiquitination. (A) Immunoblot analysis 697 of Itr1-GFP endocytosis induced with indicated concentration of inositol for 60 minutes. (B)

698 Fluorescence microscopy of $\operatorname{art} 5 \Delta$, Art5 $5^{\mathrm{WT}}$ or $\operatorname{art} 5^{K 364 R}$ cells expressing Itr1-GFP and vacuole 699 membrane marker Vph1-mCherry with or without inducing endocytosis by treating with serial 700 dilution of inositol. (C) Band densities of blots in (A) were quantified and expressed as the mean\% 701 Itr1-GFP degradation. $p<0.001, \mathrm{n}=3$. (D) doa4 4 pep $4 \Delta$ art $5 \Delta$ cells expressing Itr1-GFP and Art5 5 T 702 or $\operatorname{art} 5^{K 364 R}$ were grown to mid-log phase in synthetic medium at $30^{\circ} \mathrm{C}$. Cells were pretreated with $7030.1 \mu \mathrm{M} \mathrm{CuCl} 2$ for 4 hours to induce the Myc-Ub expression before treated with $20 \mu \mathrm{g} / \mathrm{ml}$ of inositol.

704 Cells were collected before and after 15 minutes of inositol treatment. Itr1-GFP was 705 immunoprecipitated by GFP-Trap nanobody resin. Whole cell lysate and the IP reaction was 706 resolved on 10\% SDS-PAGE gels and the blots were probed with both GFP and Myc antibodies.

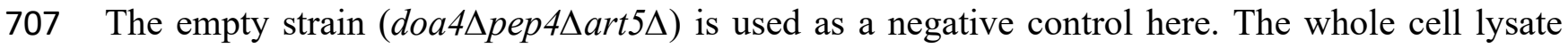


708 proteins in the left gels represent the loading control and the co-immunoprecipitated protein

709 samples were resolved in right gels. (E) IP of Itr1-GFP and blotting for Art5 ${ }^{\mathrm{WT}}$ or $\operatorname{art} 5^{\mathrm{K} 364 R}$.

710

711 Figure 3. Rsp5 PM recruitment is enhanced by Art5 ubiquitination. (A-C) Fluorescence

712 microscopy of Art5-GFP PY motif and K364R mutants in minimal media and after treating with

713 inositol for 60min. (D) Quantification of PM localization of the indicated Art5 PY motif and

714 K364R mutants. (E) Localization of GFP-Rsp5 in the presence of $A R T 5-W T$, PY motif or K364R

715 mutants before and after inositol treatment for 60min. (F) Quantification of PM localization of

716 Rsp5 in the experiment (E). (G-H) Fluorescence microscopy and quantification analysis of Art5-

717 GFP in the WT and itr $1 \Delta$ mutant condition, before and after inositol treatment. Scale bar $=2 \mu \mathrm{m}$.

719 Figure 4. K63-linked di-ubiquitination enhances the interaction between adaptor proteins and Rsp5.

720 (A) GST pull down assay between HECT-WT or F618A mutant and K63 linked Ubiquitin ladder.

721 (B) Example ITC titration curves showing the binding of Mono-Ub-WT or I44A mutant to Rsp5

722 HECT domain. (C) ITC-based measurements of the bindings between K63 di-Ub and Rsp5 HECT

723 domain. (D) The representative ITC curves of showing the binding of M1 linked di-Ub and Rsp5

724 HECT domain. (E) GST pull down assay between GST only, GST-1xUb, 2xUb or 3xUb and Rsp5

725 HECT domains. (F) Measurement of affinity between K48 di-Ub and Rsp5 HECT domain by ITC.

726 (G) ITC-based measurements showing that the K63 di-Ub with a distal end ubiquitin mutant (I44A)

727 partially disrupts the binding affinity with Rsp5 HECT domain. (H-I) IP of Art1 and Art5, WT,

728 KR and PY-motif mutants with Rsp5-HECT domain. (J-K) ITC analysis of Art1 or Art5 PY motifs

729 containing domain and Rsp5 WW1-HECT domain. (L) Analysis of binding affinity between Any1 
730 (Art1 orthologue in Pombe) and the Pub1 (Rsp5 orthologue in Pombe). (M) ITC results obtained

731 by titration of Any1 conjugated with K63 di-Ub into a solution of Pub1.

732

733 Figure 5. Deubiquitination of Art5 di-Ub by Ubp2. (A) Immunoblot analysis of Art5-3HA in the

734 indicated yeast strains: RSP5(WT), rsp5-F618A, ubp2 $\Delta$ and $r s p 5-F 618 A / \mathrm{ubp} 2 \Delta$. (B) Yeast strain

735 rsp5-F618A expressing Art5-3HA, art5 ${ }^{\mathrm{K} 364 \mathrm{R}}-3 \mathrm{HA}$ and $\operatorname{art5}{ }^{\Delta \mathrm{PY}}-3 \mathrm{HA}$ were mock treated with

736 DMSO and the cells bearing Art5-3HA were treated with MG132 $(25 \mu \mathrm{g} / \mathrm{ml})$ for 60min. (C)

737 Ubiquitin blot of rsp5-F618A yeast cells carrying Art5-3HA, as well as WT, K63R or K48R myc-

738 ubiquitin expression vector. Cells were treated with MG132 $(25 \mu \mathrm{g} / \mathrm{ml})$ for $60 \mathrm{~min}$. Samples were

739 immunoprecipirated using anti-HA antibody and analyzed by immunoblot. (D) Yeast mutants $U b$ -

$740 K 63 R$ and $U b-K 63 R / u b p 2 \Delta$ expressing Art5-3HA, $a r t 5^{\mathrm{K} 364 \mathrm{R}}-3 \mathrm{HA}$ and $a r t 5^{\Delta \mathrm{PY}}-3 \mathrm{HA}$. (E-H) models

741 depicting that Ubp2 and Rsp5 modulates the K63 di-Ub and K48 polyubiquitination of Art5

742 together: (E) K63 di-Ub of Art5 is protected from Ubp2 cleavage when engaged into exosite in

$743 R S P 5 / U B P 2$ condition. (F) Art5 remains engaged in exosite as K63 di-Ub in $u b p 2 \triangle$ mutant. (G)

744 Art5 is not engaged in the exosite but kept as K63 di-Ub in $r s p 5-F 618 A /$ ubp2 $\Delta$ condition. (H) K63

$745 \mathrm{di}-\mathrm{Ub}$ of Art5 is cleaved by Ubp2 and K48 polyubiquitin chain is instead conjugated at the K364

746 of Art5 by Rsp5 before proteasomal degradation. 


\section{Supplemental figure titles}

748 Figure S1. Art1 and Art4 undergoes K63-linked di-ubiquitination.

749 Figure S2. Ubiquitinated Art1 is required for efficient Mup1 ubiquitination.

750 Figure S3. The Art1 di-ubiquitination facilitates Rsp5 PM recruitment upon methionine treatment.

751 Figure S4. Deubiquitination of adaptor protein Art1 and Art5 by Ubp2 
752 Figure S1. Art1 and Art4 undergoes K63-linked di-ubiquitination. (A) Scheme of the Art1 domains.

753 (B) Immunoblot analysis of Art1, $\operatorname{art1}^{K 486 R}, \operatorname{art}^{\triangle P Y}, \operatorname{artl}^{\triangle P Y_{-}} 1 \mathrm{xUb}, \operatorname{art}^{\triangle P Y_{-}} 2 \mathrm{xUb}$ and $\operatorname{artl}^{\triangle P Y_{-}}$

$7543 \mathrm{xUb}$ in the wild-type strain. (C) Immunoblot analysis of Art5, art $5^{K 364 R}$, art5 $5^{\triangle P Y}$ in both the $U b$ -

$755 W T$ and $U b-K 63 R$ mutant strains. (D) Art1 is di-ubiquitinated in a K63 linkage at the residue K486.

756 (E) Art4 domain architecture. (F) Immunoblot analysis of Art4, art4 ${ }^{K 364 R}$, art4 ${ }^{\triangle P Y}$, as well as in

$757 \operatorname{art}^{\Delta P Y}-1 \mathrm{xUb}, \operatorname{art}^{\triangle P Y}-2 \mathrm{xUb}$ and $\operatorname{art}^{\triangle P Y}-3 \mathrm{xUb}$ in both the $U b-W T$ and $U b-K 63 R$ mutant strains.

758 (G) Art4 is di-ubiquitinated in a K63 linkage. The whole cell lysate protein samples were resolved

759 on 7\% SDS-PAGE gels and the blot was probed with FLAG and GAPDH antibodies.

760

761 Figure S2. Ubiquitinated Art1 is required for efficient Mup1 ubiquitination. (A) Mup1 degradation

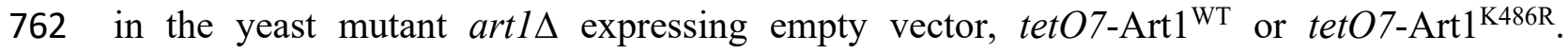

763 Fluorescence microscopy of Mup1-GFP and Vph1-mCherry with or without methionine treatment.

764 (C) Quantification of full length Mup1-GFP of the blots in (A). (D) IP of Mup1-GFP and Art1.

765

(E) IP of Mup1-GFP and Art1 ${ }^{\mathrm{WT}}$ and $\operatorname{art}^{249 R}$. (F) IP of Mup1-GFP and Art1 ${ }^{\mathrm{WT}}$ and $\operatorname{art1}^{K 486}$. (G)

766 Western blot analysis of Art $1^{\mathrm{WT}}$ and $\operatorname{art}^{K 486}$ in both WT and $n p r 1 \Delta$ mutant. (H) Western blot

767 analysis of $A r t 1^{\mathrm{WT}}$ and $\operatorname{art} 1^{K 486}$ in WT cells with rapamycin $(1 \mu \mathrm{g} / \mathrm{ml})$ or cycloheximide $(50 \mu \mathrm{g} / \mathrm{ml})$

768 treatment for 1 hour. (I) Cell growth assay of $\operatorname{art1\Delta }$ mutant expressing $\operatorname{art}^{\Delta \mathrm{PY}}$, $\operatorname{art1}^{\mathrm{K} 486 \mathrm{R}}$, Art1-

$7691 \mathrm{xUb}$, Art1-2xUb, Art1-3xUb, art $1^{\mathrm{K} 486 \mathrm{R}}-1 \mathrm{xUb}, \operatorname{art} 1^{\mathrm{K} 486 \mathrm{R}}-2 \mathrm{xUb}$ or $\operatorname{art} 1^{\mathrm{K} 486 \mathrm{R}}-3 \mathrm{xUb}$ grown at $30^{\circ} \mathrm{C}$

770 for 3 days on synthetic media containing canavanine. (J) Cell growth assay of art1 $\Delta$ mutant

771 expressing $\operatorname{art}^{\Delta \mathrm{PY}}-1 \mathrm{xUb}$, art $1^{\Delta \mathrm{PY}}-2 \mathrm{xUb}$ or $\operatorname{art}^{\Delta \mathrm{PY}}-3 \mathrm{xUb}$ grown in synthetic media with

772 canavanine at $30^{\circ} \mathrm{C}$ for 3 days.

773 
774 Figure S3. The Art1 di-ubiquitination facilitates Rsp5 PM recruitment upon methionine treatment.

775 (A-C) Fluorescence microscopy of Art1-mNeonGreen (mNG) WT, K486R and PY motif mutants

776 treated with methionine or shifted from minimal media to rich media for $1 \mathrm{hr}$. (D) Quantification

777 of Art1 recruited to PM (\%) in the experiment of (A-C), (E) Localization of GFP-Rsp5 in the

778 presence of $A r t 1^{\mathrm{WT}}$, art $1^{\mathrm{APY}}$ or $\operatorname{art} 1^{\mathrm{K} 486 \mathrm{R}}$. (F) Quantification of PM recruitment of Rsp5 in the

779 experiment (E). (G) GFP-Rsp5 PM recruitment in the yeast cells expressing MUP1, mup1 $\Delta$ or

780 mupl-Q49R mutant. (H) Quantification of the Rsp5 PM recruitment in the experiment (G).

781

782 Figure S4. Deubiquitination of adaptor protein Art1 and Art5 by Ubp2. (A) Western blot analysis

783 of Art1 ${ }^{\mathrm{WT}}$ and $\operatorname{art} 1^{K 486 R}$ mutant in the indicated yeast strains: RSP5(WT), rsp5-Y516A and rsp5-

784 F618A. (B) Western blot analysis of Art1-HTF with overexpression of yeast DUBs proteins

785 individually. (C) Western blot analysis of Art1-HTF in the $u b p 2 \Delta$ mutant bearing an empty vector,

786 or with overexpression of UBP2 or $u b p 2(\mathrm{C} 745 \mathrm{~V})$ mutant. (D) Western blot analysis of Art1-HTF

787 in yeast strains: RSP5(WT), rsp5-F618A, $u b p 2 \Delta$ and $r s p 5-F 618 A / u b p 2 \Delta$. (E) Western blot of

788 Art1-HTF in $u b p 2 \Delta$ and $r s p 5-F 618 A / u b p 2 \Delta$ yeast strains bearing an empty vector, UBP2 or ubp2(C745V) mutant. (F) Western blot analysis of tetO7-Art5-HTF in WT and $u b p 2 \Delta$ mutant with mock treatment or inositol treatment (1hr). After inositol treatment, cells were washed and grown

791 in fresh media for 3 hours. (G) Western blot analysis of tetO7-Art1-HTF in WT and $u b p 2 \Delta$ mutant

792 with or without methionine treatment $(1 \mathrm{hr})$. The methionine treated cells were then washed and 793 grown in fresh media for 3hours. $(\mathrm{H})$ Cartoon model depicting the Art1 is ubiquitinated by E3 794 ligase upon environmental cue then deubiquitinated by Ubp2. Non-ubiquitinated form of Art1 is 795 ubiquitinated at K486 residue and engaged by Rsp5 for activation. This activated form of Art1 is 796 then deubiquitinated by Ubp2 and Non-ubiquitinated form of Art1 is dis-engaged from Rsp5. 
797

798

799

800

801

802

803

804

805

806

807

808

809

810

811

812

813

814

815

816

817

818

819

820

821

822

823

824

825

826

827

828

829

830

831

832

833

834

835

836

837

838

839

References:

Alvaro CG, O'Donnell AF, Prosser DC, Augustine AA, Goldman A, Brodsky JL, Cyert MS, Wendland B, Thorner J (2014) Specific alpha-arrestins negatively regulate Saccharomyces cerevisiae pheromone response by down-modulating the G-protein-coupled receptor Ste2. Mol Cell Biol 34: 2660-2681

Aubry L, Klein G (2013) True arrestins and arrestin-fold proteins: a structure-based appraisal. Prog Mol Biol Trans/ Sci 118: 21-56

Baile MG, Guiney EL, Sanford EJ, MacGurn JA, Smolka MB, Emr SD (2019) Activity of a ubiquitin ligase adaptor is regulated by disordered insertions in its arrestin domain. Mol Biol Cell 30: 30573072

Becuwe M, Vieira N, Lara D, Gomes-Rezende J, Soares-Cunha C, Casal M, Haguenauer-Tsapis R, Vincent O, Paiva S, Leon S (2012) A molecular switch on an arrestin-like protein relays glucose signaling to transporter endocytosis. J Cell Biol 196: 247-259

Dikic I, Wakatsuki S, Walters KJ (2009) Ubiquitin-binding domains - from structures to functions. Nat Rev Mol Cell Biol 10: 659-671

Eddins MJ, Varadan R, Fushman D, Pickart CM, Wolberger C (2007) Crystal structure and solution NMR studies of Lys48-linked tetraubiquitin at neutral pH. J Mol Biol 367: 204-211

French ME, Kretzmann BR, Hicke L (2009) Regulation of the RSP5 ubiquitin ligase by an intrinsic ubiquitin-binding site. J Biol Chem 284: 12071-12079

Grenson M, Mousset M, Wiame JM, Bechet J (1966) Multiplicity of the amino acid permeases in Saccharomyces cerevisiae. I. Evidence for a specific arginine-transporting system. Biochim Biophys Acta 127: 325-338

Guiney EL, Klecker T, Emr SD (2016) Identification of the endocytic sorting signal recognized by the Art1-Rsp5 ubiquitin ligase complex. Mol Biol Cell 27: 4043-4054

Hatakeyama R, Kamiya M, Takahara T, Maeda T (2010) Endocytosis of the aspartic acid/glutamic acid transporter Dip5 is triggered by substrate-dependent recruitment of the Rsp5 ubiquitin ligase via the arrestin-like protein Aly2. Mol Cell Biol 30: 5598-5607

Hettema EH, Valdez-Taubas J, Pelham HR (2004) Bsd2 binds the ubiquitin ligase Rsp5 and mediates the ubiquitination of transmembrane proteins. EMBO J 23: 1279-1288

Ho HC, MacGurn JA, Emr SD (2017) Deubiquitinating enzymes Ubp2 and Ubp15 regulate endocytosis by limiting ubiquitination and degradation of ARTs. Mol Biol Cell 28: 1271-1283

Hofmann RM, Pickart CM (1999) Noncanonical MMS2-encoded ubiquitin-conjugating enzyme functions in assembly of novel polyubiquitin chains for DNA repair. Cell 96: 645-653

Hovsepian J, Albanese V, Becuwe M, Ivashov V, Teis D, Leon S (2018) The yeast arrestin-related protein Bul1 is a novel actor of glucose-induced endocytosis. Mol Biol Cell 29: 1012-1020

Hovsepian J, Defenouillere Q, Albanese V, Vachova L, Garcia C, Palkova Z, Leon S (2017) Multilevel regulation of an alpha-arrestin by glucose depletion controls hexose transporter endocytosis. $J$ Cell Biol 216: 1811-1831

Ing B, Shteiman-Kotler A, Castelli M, Henry P, Pak Y, Stewart B, Boulianne GL, Rotin D (2007) Regulation of Commissureless by the ubiquitin ligase DNedd4 is required for neuromuscular synaptogenesis in Drosophila melanogaster. Mol Cell Biol 27: 481-496

Kim HC, Huibregtse JM (2009) Polyubiquitination by HECT E3s and the determinants of chain type specificity. Mol Cell Biol 29: 3307-3318 
840 Kim HC, Steffen AM, Oldham ML, Chen J, Huibregtse JM (2011) Structure and function of a HECT 841 domain ubiquitin-binding site. EMBO Rep 12: 334-341

842 Komander D, Reyes-Turcu F, Licchesi JD, Odenwaelder P, Wilkinson KD, Barford D (2009)

843 Molecular discrimination of structurally equivalent Lys 63-linked and linear polyubiquitin chains.

844 EMBO Rep 10: 466-473

845 Konstas AA, Shearwin-Whyatt LM, Fotia AB, Degger B, Riccardi D, Cook DI, Korbmacher C, Kumar $846 \mathrm{~S}$ (2002) Regulation of the epithelial sodium channel by N4WBP5A, a novel Nedd4/Nedd4-2847 interacting protein. J Biol Chem 277: 29406-29416

848 Lauwers E, Jacob C, Andre B (2009) K63-linked ubiquitin chains as a specific signal for protein 849 sorting into the multivesicular body pathway. J Cell Biol 185: 493-502

850 Leon S, Erpapazoglou Z, Haguenauer-Tsapis R (2008) Ear1p and Ssh4p are new adaptors of the 851 ubiquitin ligase Rsp5p for cargo ubiquitylation and sorting at multivesicular bodies. Mol Biol Cell 852 19: 2379-2388

853 Li M, Rong Y, Chuang YS, Peng D, Emr SD (2015) Ubiquitin-dependent lysosomal membrane

854 protein sorting and degradation. Mol Cell 57: 467-478

855 Lin CH, MacGurn JA, Chu T, Stefan CJ, Emr SD (2008) Arrestin-related ubiquitin-ligase adaptors 856 regulate endocytosis and protein turnover at the cell surface. Cell 135: 714-725

857 MacDonald C, Shields SB, Williams CA, Winistorfer S, Piper RC (2020) A Cycle of Ubiquitination 858 Regulates Adaptor Function of the Nedd4-Family Ubiquitin Ligase Rsp5. Curr Biol 30: 465-479 859 e465

860 MacDonald C, Stringer DK, Piper RC (2012) Sna3 is an Rsp5 adaptor protein that relies on 861 ubiquitination for its MVB sorting. Traffic 13: 586-598

862 MacGurn JA, Hsu PC, Emr SD (2012) Ubiquitin and membrane protein turnover: from cradle to 863

864

865 grave. Annu Rev Biochem 81: 231-259

866 MacGurn JA, Hsu PC, Smolka MB, Emr SD (2011) TORC1 regulates endocytosis via Npr1-mediated phosphoinhibition of a ubiquitin ligase adaptor. Cell 147: 1104-1117

867 Maspero E, Mari S, Valentini E, Musacchio A, Fish A, Pasqualato S, Polo S (2011) Structure of the HECT:ubiquitin complex and its role in ubiquitin chain elongation. EMBO Rep 12: 342-349

869 Myat A, Henry P, McCabe V, Flintoft L, Rotin D, Tear G (2002) Drosophila Nedd4, a ubiquitin ligase, is recruited by Commissureless to control cell surface levels of the roundabout receptor. Neuron 35: 447-459

871 Nikko E, Pelham HR (2009) Arrestin-mediated endocytosis of yeast plasma membrane 872 transporters. Traffic 10: 1856-1867

873 O'Donnell AF, Huang L, Thorner J, Cyert MS (2013) A calcineurin-dependent switch controls the

874 trafficking function of alpha-arrestin Aly1/Art6. J Biol Chem 288: 24063-24080

875 Ohtake F, Tsuchiya H, Saeki Y, Tanaka K (2018) K63 ubiquitylation triggers proteasomal 876 degradation by seeding branched ubiquitin chains. Proc Natl Acad Sci U S A 115: E1401-E1408

877 Rotin D, Kumar S (2009) Physiological functions of the HECT family of ubiquitin ligases. Nat Rev $878 \mathrm{Mol}$ Cell Biol 10: 398-409

879 Saeki Y, Kudo T, Sone T, Kikuchi Y, Yokosawa H, Toh-e A, Tanaka K (2009) Lysine 63-linked 880 polyubiquitin chain may serve as a targeting signal for the 26S proteasome. EMBO J 28: 359-371 881 Sardana R, Zhu L, Emr SD (2018) Rsp5 Ubiquitin ligase-mediated quality control system clears 882 membrane proteins mistargeted to the vacuole membrane. J Cell Biol 
883

884

885

886

887

888

889

890

891

892

893

894

895

896

897

898

899

900

901

902

903

904

905

906

907

908

909

910

911

912

Sato Y, Yoshikawa A, Yamagata A, Mimura H, Yamashita M, Ookata K, Nureki O, Iwai K, Komada M, Fukai S (2008) Structural basis for specific cleavage of Lys 63-linked polyubiquitin chains. Nature 455: 358-362

Sato Y, Yoshikawa A, Yamashita M, Yamagata A, Fukai S (2009) Structural basis for specific recognition of Lys 63-linked polyubiquitin chains by NZF domains of TAB2 and TAB3. EMBO J 28: 3903-3909

Schild L, Lu Y, Gautschi I, Schneeberger E, Lifton RP, Rossier BC (1996) Identification of a PY motif in the epithelial $\mathrm{Na}$ channel subunits as a target sequence for mutations causing channel activation found in Liddle syndrome. EMBO J 15: 2381-2387

Shih SC, Sloper-Mould KE, Hicke L (2000) Monoubiquitin carries a novel internalization signal that is appended to activated receptors. EMBO J 19: 187-198

Sims JJ, Cohen RE (2009) Linkage-specific avidity defines the lysine 63-linked polyubiquitinbinding preference of rap80. Mol Cell 33: 775-783

Sloper-Mould KE, Jemc JC, Pickart CM, Hicke L (2001) Distinct functional surface regions on ubiquitin. J Biol Chem 276: 30483-30489

Spence J, Sadis S, Haas AL, Finley D (1995) A ubiquitin mutant with specific defects in DNA repair and multiubiquitination. Mol Cell Biol 15: 1265-1273

Swaney DL, Beltrao P, Starita L, Guo A, Rush J, Fields S, Krogan NJ, Villen J (2013) Global analysis of phosphorylation and ubiquitylation cross-talk in protein degradation. Nat Methods 10: 676682

Tsui C, Raguraj A, Pickart CM (2005) Ubiquitin binding site of the ubiquitin E2 variant (UEV) protein Mms2 is required for DNA damage tolerance in the yeast RAD6 pathway. J Biol Chem 280: 19829-19835

Yashiroda H, Oguchi T, Yasuda Y, Toh EA, Kikuchi Y (1996) Bul1, a new protein that binds to the Rsp5 ubiquitin ligase in Saccharomyces cerevisiae. Mol Cell Biol 16: 3255-3263

Zhu L, Jorgensen JR, Li M, Chuang YS, Emr SD (2017) ESCRTs function directly on the lysosome membrane to downregulate ubiquitinated lysosomal membrane proteins. Elife 6

Zhu L, Sardana R, Jin DK, Emr SD (2020) Calcineurin-dependent regulation of endocytosis by a plasma membrane ubiquitin ligase adaptor, Rcr1. J Cell Biol 219 
A

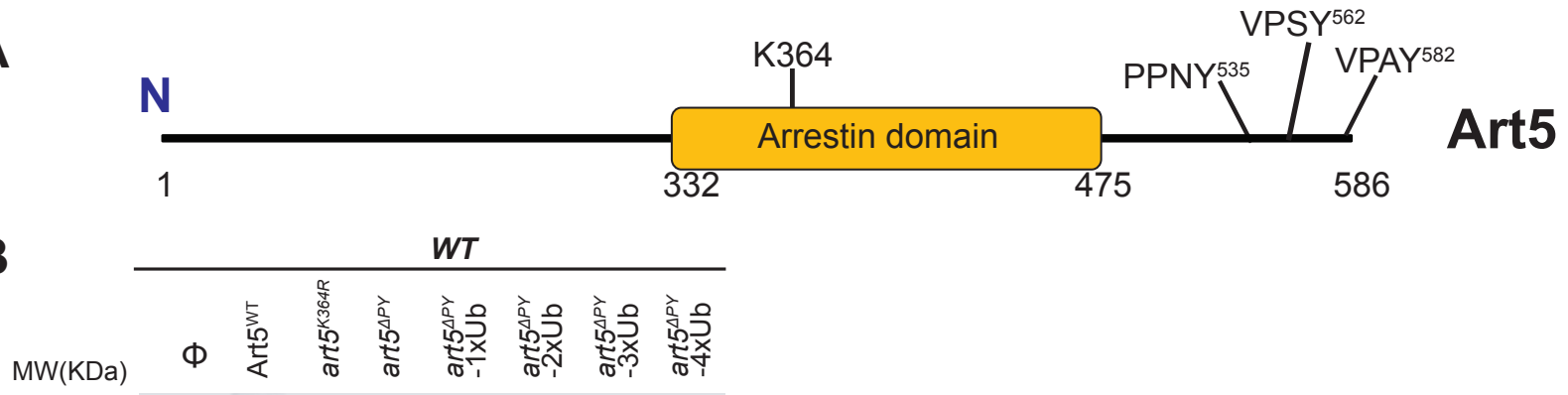

B
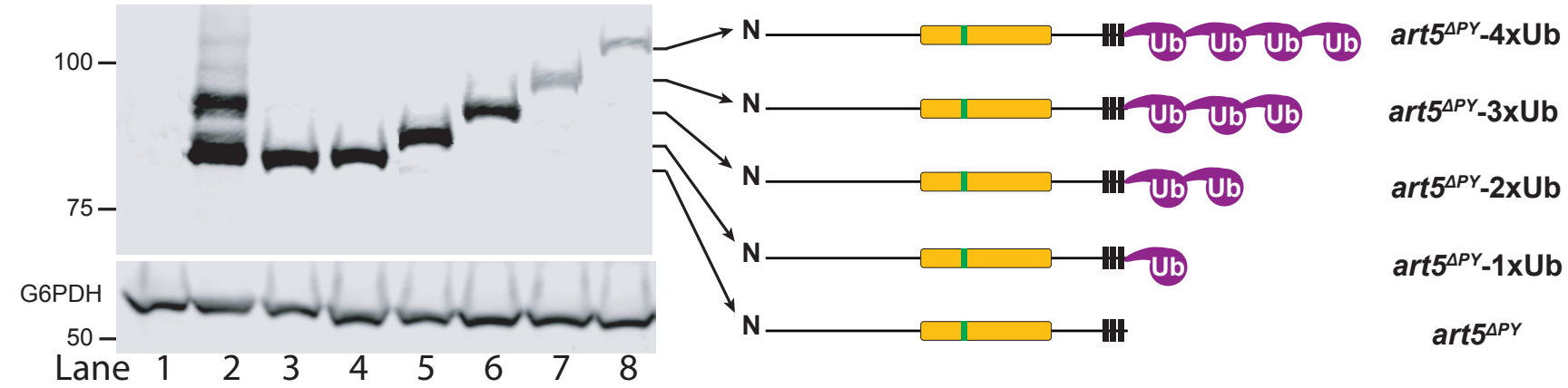

C

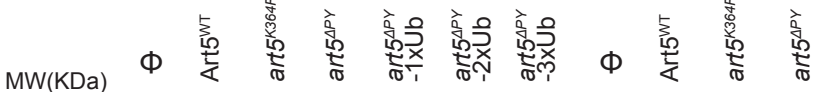
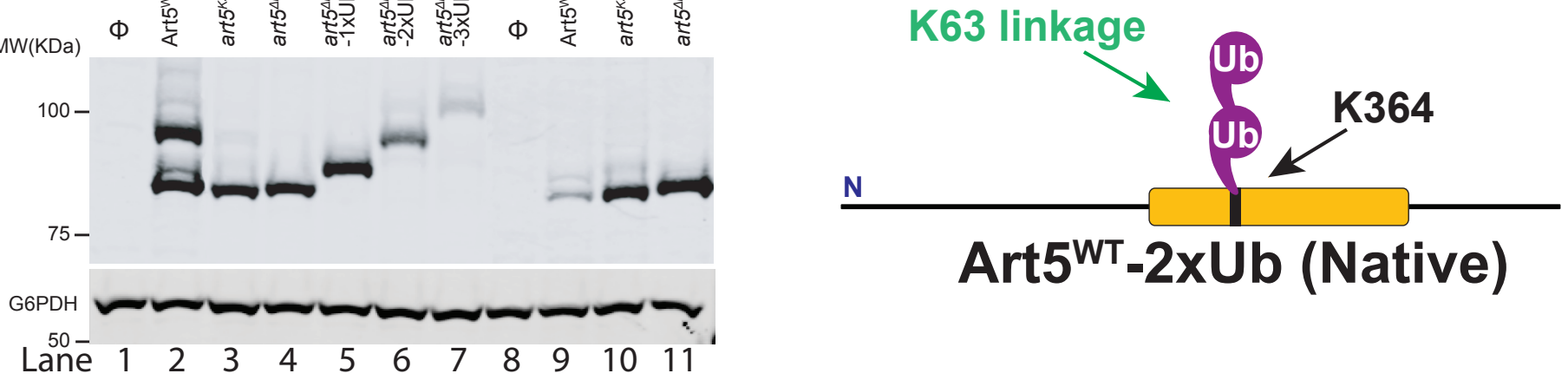

Figure 1 
A

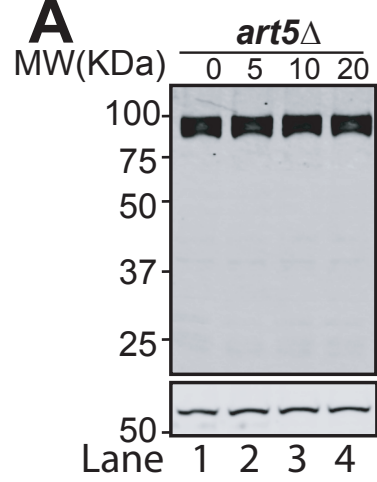

B

Inositol

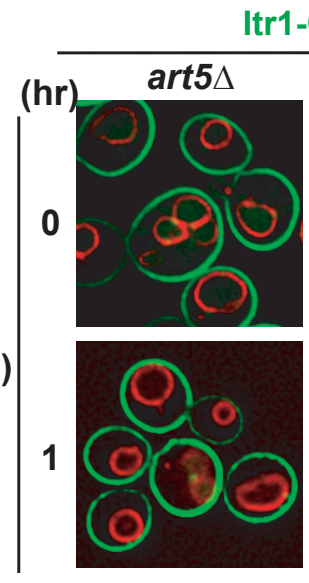

Itr1-GFP/Vph1-mCherry
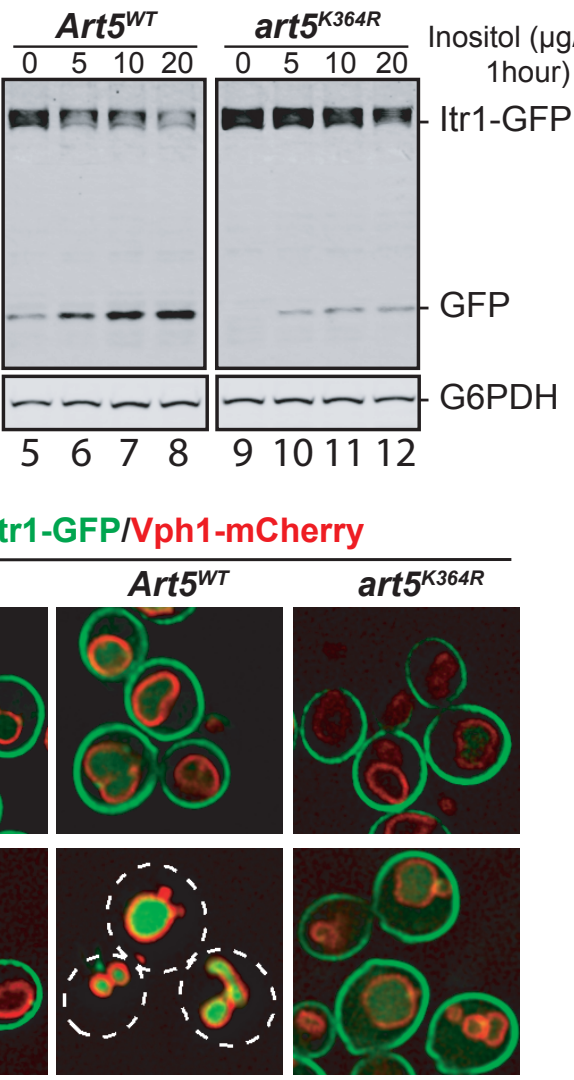

$\operatorname{art5}^{K 364 R}$
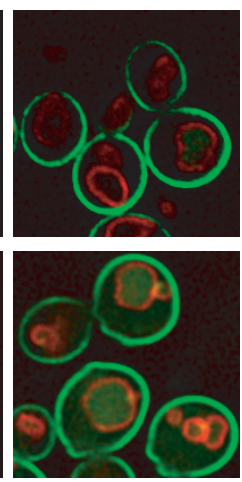

C

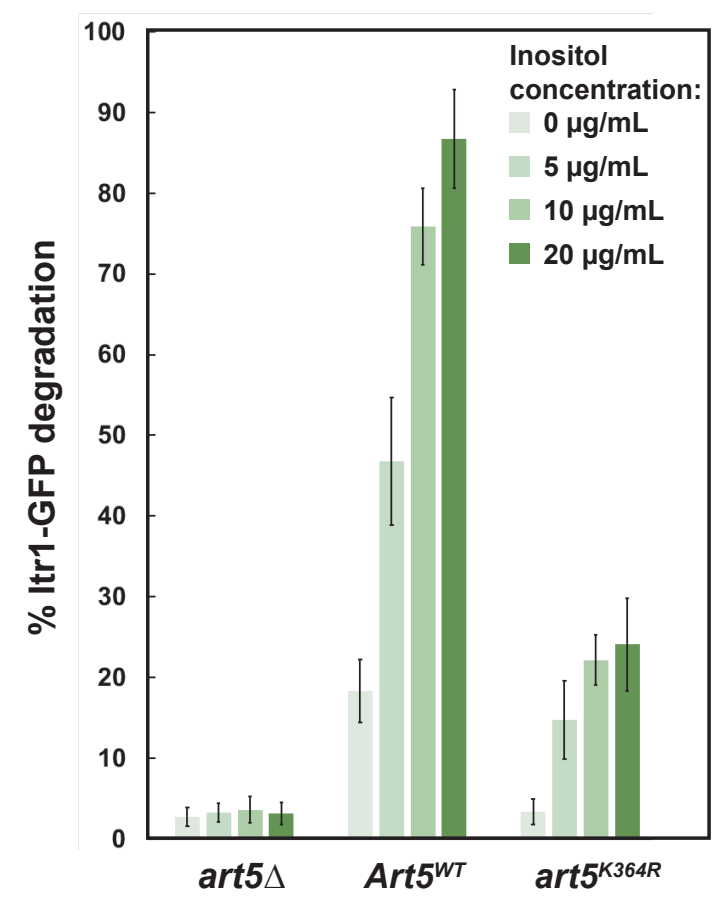

D
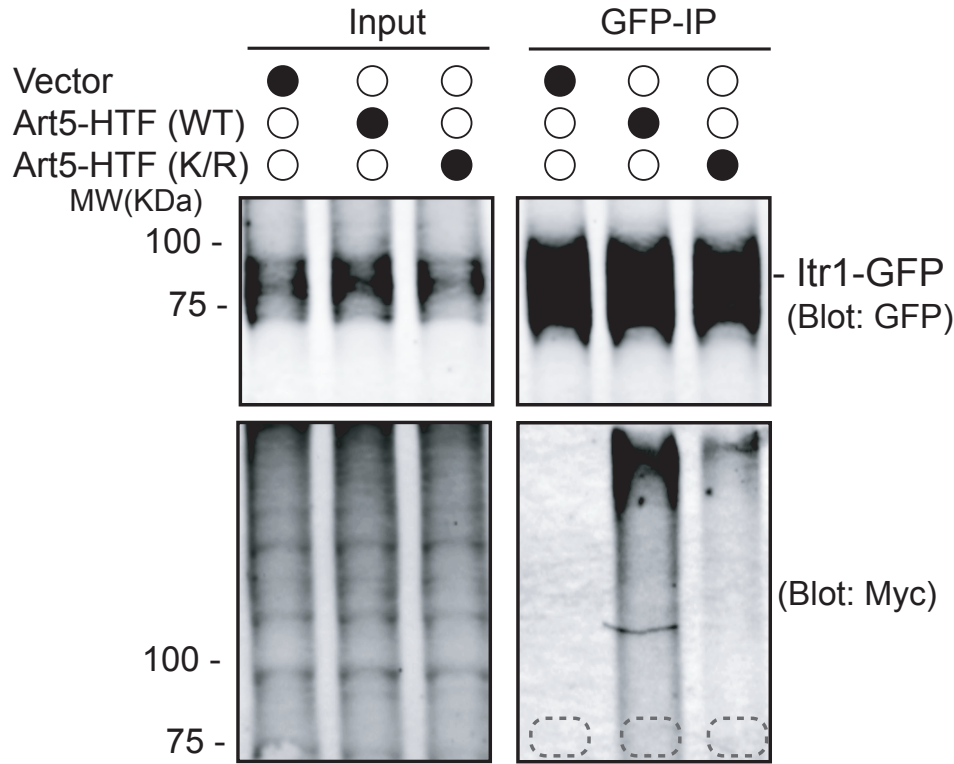

E

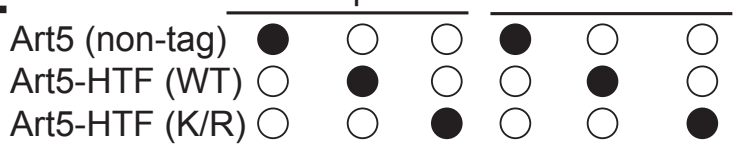

$\mathrm{MW}(\mathrm{KDa})$
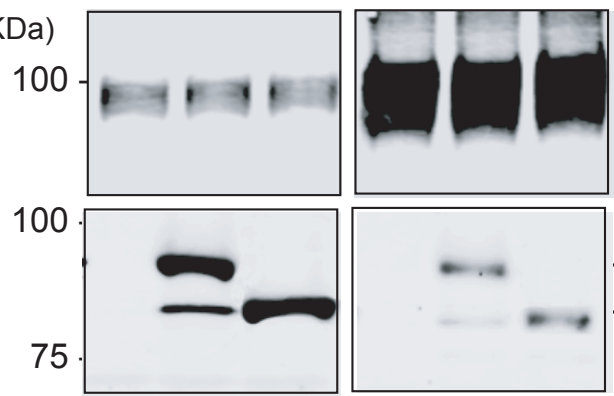

Itr1-GFP

(Blot: GFP)

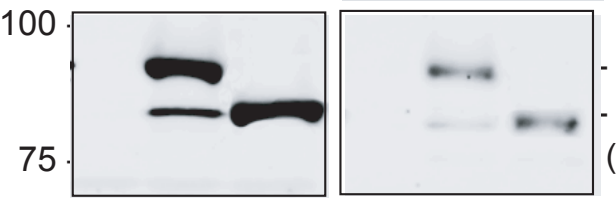

Art5-diUb

- Art5

(Blot: FLAG)

F

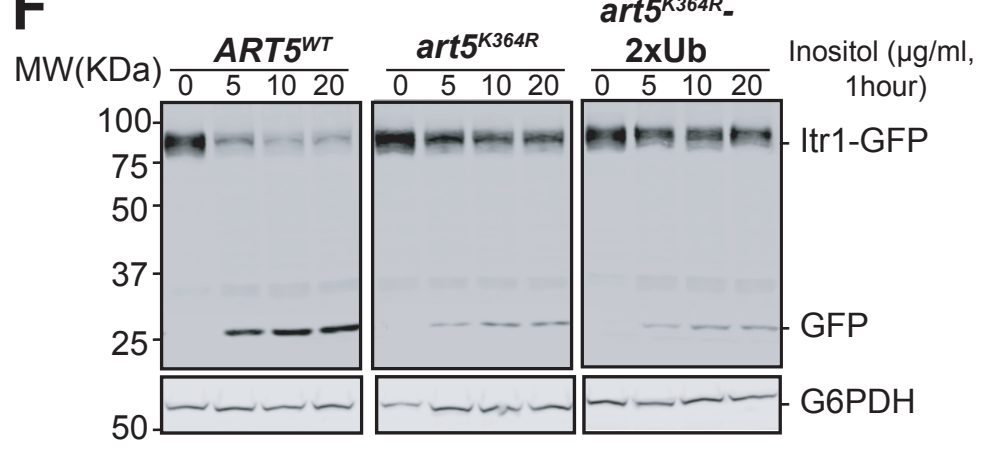



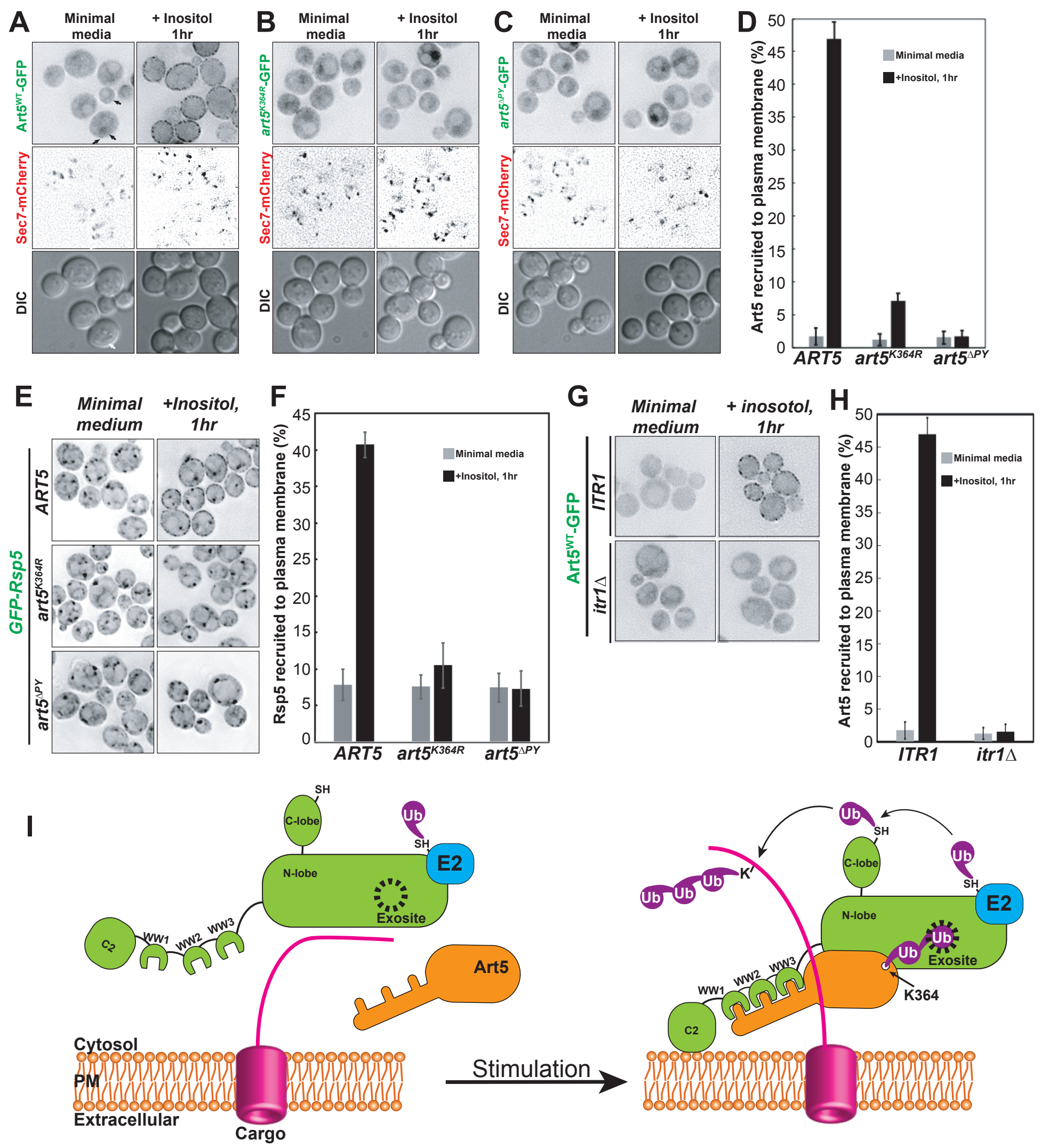

Figure 3 

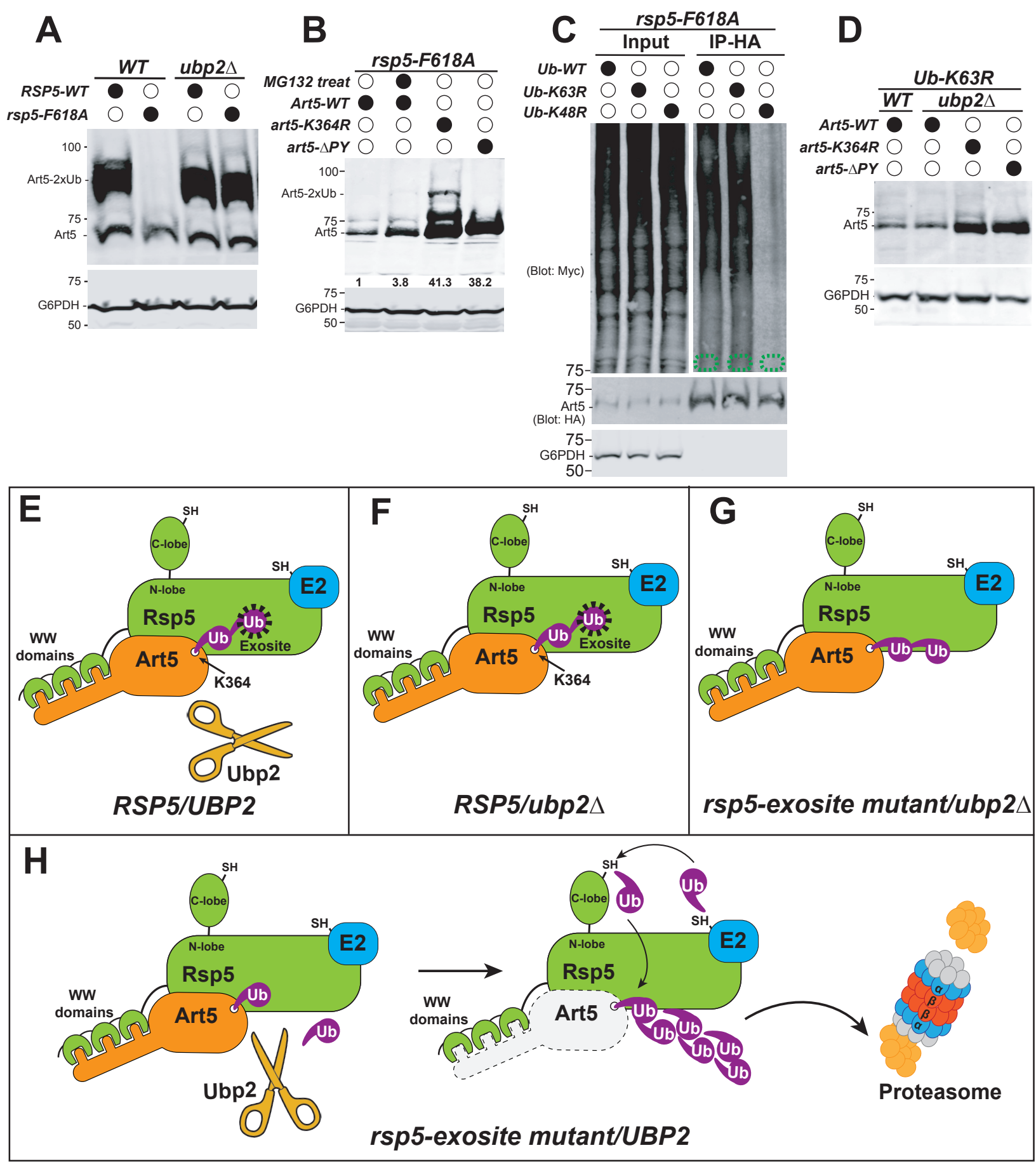

Figure 5 